\title{
BIM-Based Educational and Facility Management of Large University Venues
}

\author{
Rubén Muñoz Pavón ${ }^{1}\left(\mathbb{D}\right.$, Antonio A. Arcos Alvarez ${ }^{2}(\mathbb{D}$ and Marcos G. Alberti $1, * \mathbb{C}$ \\ 1 Departamento de Ingeniería Civil, Construcción, E.T.S de Ingenieros de Caminos, Canales y Puertos, \\ Universidad Politécnica de Madrid, 28040 Madrid, Spain; ruben.mpavon@upm.es \\ 2 Departamento de Ingeniería y Morfología del Terreno, E.T.S de Ingenieros de Caminos, Canales y Puertos, \\ Universidad Politécnica de Madrid, 28040 Madrid, Spain; antonio.arcos@upm.es \\ * Correspondence: marcos.garcia@upm.es; Tel.: +34-91-0674121
}

Received: 6 October 2020; Accepted: 4 November 2020; Published: 10 November 2020

\begin{abstract}
The aim of this paper was to provide a Building Information Modeling (BIM)-based management system for the Civil Engineering School (ETSICCP) at the Universidad Politécnica de Madrid with a long-term development perspective. A Building Information Modeling (BIM) management system for complex infrastructure facilities demands a detailed 3-Dimensional model according to future management requirements. In this study, the infrastructure of the ETSICCP was modeled on various phases and synchronized with not only external educational information but also with facility management (FM) parameters. The methodology followed in this study ranges from the blank paper to a BIM-based detailed FM system oriented to educational scheduling throughout the infrastructure providing real time information synchronized with spreadsheets and a 3-D model. The result of this paper provides multiples future management lines, like COVID-19 BIM-management or synchronization with local public transports' applications (mainly metro and bus transport systems), through a public accessible Application Programming Interface (API). The significance of this research relies on the generation of an information and management system, based on a BIM model of a university campus. This project was designed for all the agents involved in its operation, students, lecturers, and managers. All these agents have a level of access appropriate to their needs and functions within the institution.
\end{abstract}

Keywords: building information modeling BIM; BIM infrastructure; BIM data management; facility management; monitoring systems

\section{Introduction}

Building Information Modeling (BIM) is defined as a methodology of collaborative scope able to create an application environment that can host all the disciplines involved in a construction project with a great amount of information either ascribed or applicable to the different project stages, i.e., design, construction and service and maintenance management.

Under the concept of BIM multiple definitions are collected, such as the one given by ISO 29481-1:2010, which defines BIM as a digital representation of functionalities and characteristics of every built element. Most common research points BIM to a methodology of collaborative scope that hosts all disciplines and related information pertinent to a project development and the required execution phases. Each execution phase requires different types of information. This information can also be useful in future stages of the infrastructure life, using the BIM model as a tool for efficient management with accurate information [1] or even more considering possible future demolition phases [2,3]. This way, in any episode of the project life, a large amount of information is available due 
to the inclusion of all disciplines involved, making BIM a way to represent the entire reality of the infrastructure [3,4] using the BIM model as a central information repository [3,5-8].

BIM requires a constant interaction and, therefore, provides an ensured efficiency between the different branches or disciplines affecting the project, starting with a 2-D environment on many occasions, and followed by budget activities, scheduling, management, and future maintenance.

This broad framework covers all phases of the project where BIM is involved. The implementation of new technologies, such as the Internet of Things (IoT), stand out for their relevance, especially in terms of management, and have become an attractive alternative to traditional tools.

The use of BIM methodology in all project phases involves several advantages, mainly in the early detection of project errors or mistakes and comprehension of all disciplines related to the project. The advantages of BIM methodology compared with the traditional workflow is clearly shown in the graphic presentation of MacLeamy curves [9]. The reference shows that if the error detection occurs in earlier moments of the project, significant correction costs in later stages, or even in the construction phases, can be saved.

Great improvements have been achieved in BIM methodology for every project phase. The existing skills for the in-service management of the infrastructure have special importance but there are also important progress steps for the construction stage in which the BIM methodology allows a constantly updated model of the construction works to be on hand [10]. However, this application entails constant interaction with the BIM model and continuous information review. Thus, this process demands detailed scheduling in order to achieve a daily updated BIM model. Similarly, the implementation of technologies, such as IoT, permit monitoring heavy loads or dangerous areas during the construction time and creating automatic frameworks for information and communication purposes [11]. Regarding the design stage, one of the most important features is the synthesis of the data ascribed to the infrastructure (BIM) in relation to the environment data Geographic Information System and Internet of Things (GIS and IoT). The combined information allows a more reliable decision-making by the designer, improving the project location and properties [12].

Further to these examples, the development of a service management system of the infrastructure must be highlighted. The application of BIM stands out in hospital infrastructure facilities, airports or university campus [13] for space management. This is because most BIM applications are related to new infrastructure [3,14-18] instead of already existing buildings [19,20]. However, advanced society requirements, such as sustainability, have created a new tendency in implementing BIM for existing buildings [19-24].

Hence, a BIM-based FM system for complex infrastructure facilities demands a detailed 3-Dimensional model according to future management requirements. For this study, the infrastructure of the Civil Engineering School (ETSICCP) at Universidad Politécnica de Madrid (UPM) was modeled in various phases and synchronized with not only external educational information but also with the most important management parameters. Beginning with 2-dimensional Computer-Aided Design (CAD) information as a starting point, the modeling process was divided into two different groups as a function of the level of information (LOI) required. The LOI of the elements were defined as a function of the future management needs. This was detailed by means of the BIM Execution Plan (BEP) that was performed at the beginning. Following the main points of ISO $19650[25,26]$, a higher LOI was selected for accessible public areas and all classrooms in the building while a lower LOI was considered sufficient for spaces where access is restricted, such as technical laboratories or private offices. Once the base model was reached, the implementation of information and synchronizing process began. Additionally, the implementation of new technologies, such as IoT, was considered, providing the capacity of issuing in real-time data, Geographical Information Systems (GIS) providing Universal Transverse Mercator (UTM) coordinates to the model or BIG DATA management databases supporting the entire flow of BIM information. This process provides a global concept of implementing BIM methodology in already existing buildings with no previous BIM information. Modeling from zero, considering future management needs, made the modeling and information implementation to 
the model much more complex. However, the most important challenge of this project was to provide access to all management members who traditionally work with standard management protocols.

This paper shows the beginning of a long-term development system with near future implementations of the BIM management system. The study is based on the building of the ETSICCP, opened in 1968, that consists of a total area of $38,970.84 \mathrm{~m}^{2}$, of which $32,631.23 \mathrm{~m}^{2}$ are usable space for more than 4000 students that are enrolled in Bachelor's Degrees, Master's Degrees, and Doctorate programs. This information shows the magnitude of the school model and the important opportunity of implementing the existing advances and the benefits of BIM for the service, teaching, and management staff, considering the improvements that can be achieved by the use of the BIM methodology, quite different to the traditional methods. The development of a new BIM-based FM system into the mentioned infrastructure, could provide real time information in terms of reservation of classrooms or sports facilities. Moreover, real time parameters, such as occupation or availability of spaces, are quite interesting for management staff of the building. Future systems to combat COVID-19 could be implemented and handling spaces and internal movements could be tracked and saved solving the problem of unknown internal paths with more intensity along the day. Overall, the objective of this research was to provide the first management system tracking real time educational parameters and providing a BIM model with all the requirements needed to allow it to host new future management demands. The management based on BIM of such a complex infrastructure, with more than 50 teaching rooms, 21 laboratories, and 4000 students, can provide multiple benefits. With the BIM-based management methodology that has been developed, some social barriers can be overcome. For the first time, BIM benefits are not only available for the management staff but also for any other entity involved in the daily usage of the building. Real-time information, COVID management, facilities, bookings, BIM, and sensor synchronization, as well as university assets location, are now accessible through internet to all users. As a result, a living organism of the infrastructure is obtained with different degrees of accessibility depending on the users, whether they are the students, the teaching staff, or the managers of the ETSICCP.

\section{Literature Review}

The BIM model was focused on the infrastructure management of the ETSICCP. In this way, the BIM model needed to house a large amount of data [19-21] and to enable the provision of useful information related to updated drawings [3], quality control [27,28], space and energy management [19,29], or emergency situations [20]. Under this scope, BIM enhances its efficiency due to the incorporation of new technologies, like IoT, linking, and synchronizing with databases or 3-D scanning information ascribed to the model. Facing the synthesis of methodologies of such unequal nature, it gives rise to ontological problems based on the existing incompatibility of the generated information.

\subsection{BIM and IoT Management}

The development of this binomial status is an important feature to be implemented in the near future. The background records of the union of IoT and BIM models show notorious advantages in terms of infrastructure management based on different software developments [10]. The combination of BIM and IoT permits a large amount of real-time information to be available and this is the core of what is called Smart City [30,31]. Assuming Smart City to be an extension of Digital City, the main point of this concept is the digital environment. In such a sense, a BIM model synchronized with public transport systems, public parking or climate control applications provides the user with accessible information, not only about the infrastructure, but also about the Smart City in which it is integrated and in a homogeneous way.

Together, BIM and IoT shape a system synthesis applicable to all project phases with outstanding results, such as those shown for highway maintenance, by leveraging Big Data and BIM [32]. For the diffusion and application of this combined technology some common standards have been developed [10] with the goal of creating new beneficiaries of BIM, including the future occupants of 
the infrastructure who are unaware of the full potential of a useful operation of BIM information [33]. For that purpose, some standards have been developed in order to obtain different data types so that they are useful for future infrastructure management based on simple and intuitive interfaces [34].

The ETSICCP model contemplates the possibility of hosting IoT by means of sensor systems able to provide real time information to a database getting close to the concept of "Smart Building" [35] with great operation efficiency in terms of information handling [36,37] improving BIM information with real time data extremely important in special infrastructure, such as a Campus, airports, or even hospitals [38,39].

\subsection{3-D Scanning}

BIM usage is strongly associated with preconstruction phases, such as predesign, design, or even construction. However, new development points to postconstruction phases have appeared [2,3,19,40-42]. Infrastructure management requires big volume of detailed data in order to achieve an efficient management system [1], making capture of data a critical step in order to achieve useful information for future managements based on standard frameworks for each management target [43].

If the capture of data supplies insufficient information for initial proposals, obtaining new complete data means large economic and time costs [20,44-48]. To avoid this, data capture techniques are commonly used in existing building with the imaged-based or range-based techniques $[4,49]$, usually executed with a laser scanner, standing out.

Given the progress of laser scanner methodology in the field of Cultural Heritage $(\mathrm{CH})$ it has become an attractive alternative in order to create three-dimensional models from existing buildings or other constructed elements. Some remarkable cases are: the digital model of Pietá of Michelangelo Buonarrotti [50], the implement of a digital model of Nuestra Señora de los Desamparados [51], modeling of Minerva statue [52], the 3-D model of a Terracotta piece [53], and the elevation model of the lost ruins of the Coliseum in Rome [54]. This technology has been termed as Scan-to-BIM, and it is based on the process of capturing the main features and geometry of existing buildings or infrastructure in order to create a BIM model without any previous data. The most common technology used for this purpose is three-dimensional laser scanning.

A great deal of progress has been made by the use different scanning techniques developed in recent years, ranging from pure $\mathrm{CH}$ related techniques [55], focused on architectural, archaeological, and geological elevations [56], to more detailed ones, as well as aspects, such as point cloud processing [57], improvements of the optical triangulation [58-60], camera calibration as a function of the position [56,57], or the simplification of point-defined surfaces [61].

Highlighting the important evolution of the laser scanner as a source of information for BIM, research points to "scan-to-BIM" developments based on modeling the collected information in an automated way $[4,47,62-64]$.

The BIM model developed and herein reported was devised based on CAD information but this does not impede the future scanning of the building and the implementation to the model of the collected information. With the obtained data, point clouds and images will allow the verification of the initial CAD files and issue image patterns in the model useful for virtual internal routing.

\subsection{BIM and Facility Management}

The distinctive concept of this project fully contemplates the techniques and research developed under the denomination of Facility Management (FM) based on real applications of BIM management methodologies in special infrastructure facilities [38,39]. The set-up of the 3-D model is considered as the database element in which the FM tools will be developed $[65,66]$. Although the number of tools referred to the infrastructure management database stands out, there are also great advantages in the implementation of BIM tools at earlier phases $[67,68]$. The inter-operability between different data sources, independently of the original stage or phase [68], is the main objective in the standard 
development, either for modeling or for the information management itself [69], thereby reducing the typical inter-operation framework in the construction industry [70].

The reason for the existence of the FM tools is based on completing the voids existing between BIM and the infrastructure management [71], providing a much more efficient methodology for building management [5,72]. Many compilations of FM techniques [73] or simple guidelines for different disciplines or involved entities improve the implementation of BIM in management stages [74,75].

The scope for this research in terms of application of FM tools is based on the Computer Aids Facility management (CAFM) with software tools in fields, such as firefighting [76], energy management [77], or real visualization and interaction with the model [78].

\subsection{Educational Management in Universities}

The management of university campuses differs depending on the nature of the institution. The infrastructure of this paper is considered a public institution facility. Thus, previous research published dealing with public infrastructure managements was gathered in this literature review.

Several publications have studied the management of important public institutions focusing on the FM and highlighting the importance of this. Jensen, in 2011 [79], argued that, while core business should add value to external customers, FM must create value for internal customers by supporting the core business. Another definition of FM is detailed by the Corporate Real Estate [80], assuming it to be an act of aligning the services with the main purpose of the infrastructure.

The exploitation and maintenance of facilities are considered to be the second largest cost of universities, ranging between $5-15 \%$ in Europe [81]. Various studies indicate that university facilities are designed with large capacity spaces but their utilization rates remain only within a range of from 20 to 40\% [82-85]. Moreover, most university facilities in Europe were built in the 1960s and the 1970s, resulting in poor technical conditions with outdated designs for 2020.

Smart Campus is the main goal in terms of modern universities. The process comprises of three stages: traditional campus, e-campus, and digital campus as the final phase [86]. The traditional campus is based on a classical management where students and faculties need to meet face to face to share content. Related to FM, the traditional campus mainly relies on paper formats to manage spaces or other facilities in the whole campus. To reach the e-campus phase, the use of internet to disseminate the material to be learned should be widespread $[86,87]$. Digital campus demands a technical environment with IoT, mobile terminal accessing, radio frequency identification (RFID), and cloud computing.

Many advantages have been published in terms of digital campus profits. Energy management [88] and reductions of electricity cost [89], improving the interaction with other campuses and detailed management of university assets [89] or providing map information of the campus for location purposes [89]. All these benefits are attainable thanks to the implementation of technologies, such as RFID [86,89-95], IoT [86-89,94,96,97], 3-D visualization [98], sensors application [88,89,95,97-99], or web service $[94,96,98]$.

In this context, this paper details the firsts steps to be taken at the ETSICCP and the UPM to approach the digital campus environment, employing BIM together with the technologies cited previously.

\section{Methodology}

The staff and teaching facilities of the Civil Engineering School (Escuela Técnica Superior de Ingeniería de Caminos, Canales y Puertos in Spanish) were moved in 1968 to the present infrastructure within the UPM Campus that today hosts these engineering studies. For more than 50 years, the infrastructure has experienced several changes inside the building, mainly in the use of classrooms and other spaces. These changes, along with the room geometry changes for change of use purposes, have not been recorded or documented. This situation is hardly plausible with a BIM model. The goal for developing this BIM model is to issue a useful tool for the school management, not only in terms of modifications records [3] but also for the rational use of spaces [19,29]. The idea of unifying static 
information (classroom capacities, existing connections, and fixed equipment) and dynamic information (such as lecture sessions or locker assignments) into the one database allows for totally accessibility for the staff personnel in charge of the ETSICCP management. However, developing a new management methodology implies some risks. New management not only needs to be more efficient than its predecessor, but it must also be developed by the same professional staff. With this idea as a starting point, the complexity and magnitude of the infrastructure also increments the mentioned risk. In this project, a total area of $38,971 \mathrm{~m}^{2}$ was considered. More than 50 teaching rooms, 21 laboratories, and more than 4000 students are managed. This building hosts two doctoral programs, five master's degrees, and two bachelor's degrees. The school is one of the oldest civil engineering schools in the world, declared 5th by the Academic Ranking of World Universities 2020 in the field of Civil Engineering [100]. In this context, the BIM-based methodology developed in this study brings additional profits:

- Total accessibility to BIM infrastructure model. The BIM methodology allows for the possibility of accessing the information through internet by all the entities involved. This allows the user to access the facilities and environment properties of the infrastructure in one single platform.

- Real data information. The information is accessible and updated. Locker occupation, sports and teaching installation reservations, public transports scheduling, room enumeration, and location or current space occupation are provided. Graphical visualization of teaching schedules and exam room management is provided by the BIM model hosted on the accessible webpage.

- COVID management. As a new management developed, new availability of all spaces for the academic course 2020/2021 has been carried out. Real space distribution taking into account all geometric room characteristics is detailed with the highest level thanks to the BIM model.

- Sensors synchronization. Real time information collected by sensors are linked with SQL databases which, at the same time, are synchronized with the BIM model, providing the user with all the information assigned to specific location in the infrastructure and in a graphical way.

- University assets location and registration. The methodology developed provides the UPM with the possibility of registering all University equipment and its real location.

\subsection{BIM-EDU Project}

The development of the above cited 3-D BIM model of the ETSICCP has its origin in a broader project called BIM-EDU. The BIM-EDU Project objective is the production of a 3-D model of ETSICCP located in the campus of UPM and enables the integration of all the information of interest for the management staff for the use of the buildings or for educational purposes. This BIM model will help the management staff of the school, will improve the academic life of students, will make the teaching work of the lecturers easier, and will integrate the work of the Service and Administration Personnel (PAS).

The project involves a team of students from the module Smart Construction which is part of the master's degree in Civil Engineering. Said students were also working on their Final Master Thesis (TFM). The objective is to provide a solution that firstly satisfies all the real needs of this academic institution and serves as good training for the developers providing innovative proposals, thereby improving the quality of teaching. It is, therefore, a project consisting of several stages, starting with collecting information and generating a large amount of information that would grow or be reduced depending on the stage. The BIM-EDU Project was developed as a Design-thinking initiative [101].

BIM-EDU project could be divided in two main points, as seen in Figure 1: Infrastructure Modeling and BIM-based FM. Infrastructure modeling housed not only its own model creation but also collected all the retrieving information system. Thus, BIM-based FM included the infrastructure information flow through BIM model to final users.

\subsection{Modeling and Management}

The methodology adopted for the execution of this project consisted of several phases defined in the BEP in which different aspects were addressed together and resulted in one efficient model 
based on BIM methodology. This project was focused on research and the development of an efficient BIM management methodology, only the main points related to UNE-ISO 19650-1 [25] and UNE-ISO 19650-2 [26] being considered. Asset Information Requirements (AIR) and Project Information Requirements (PIR) were also detailed in BEP. Given the nature of this project, other points, such as a responsibility matrix or Organization Information Requirements related to legal issues, were not considered. The phases were independently developed by having temporal coincidence, as is shown in Figure 2.
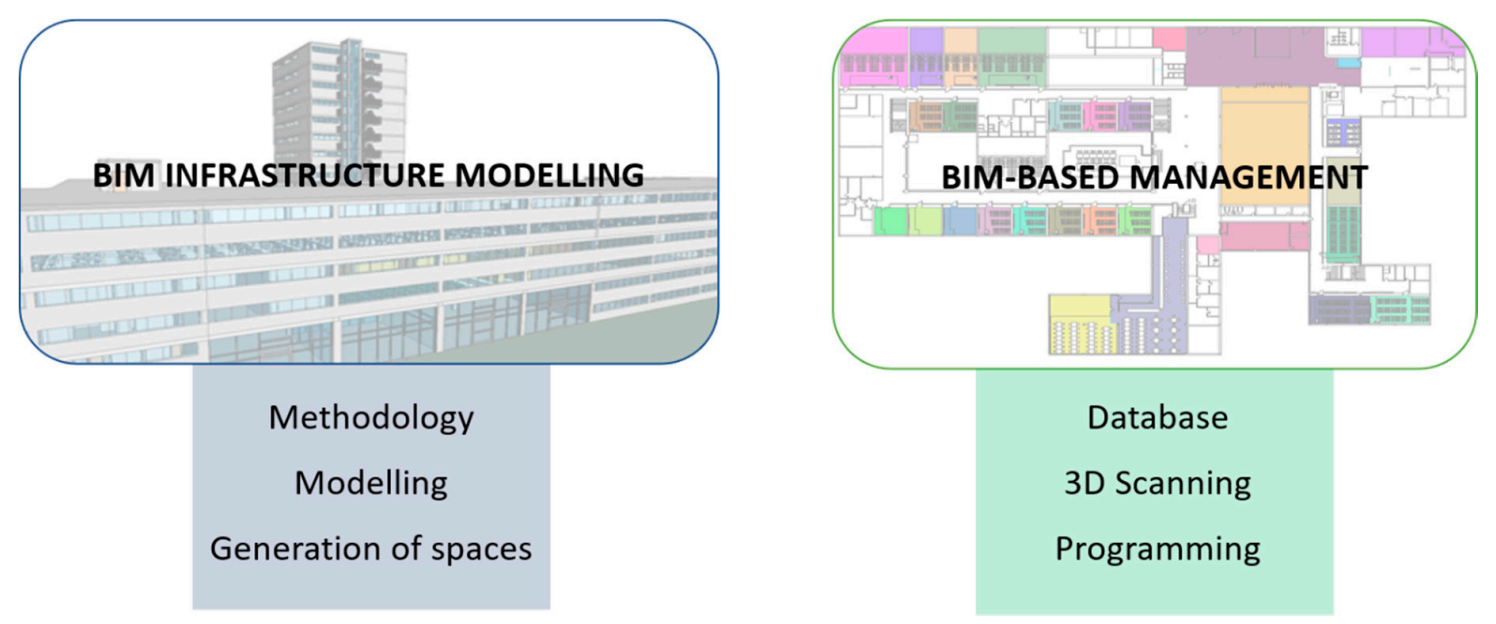

Figure 1. Flow chart Building Information Modeling (BIM)-EDU project.

The overall process is comprised of the following stages:

(a) Modeling stage: was the longest phase because of the size of the infrastructure. This phase was sub-divided to improve efficiency depending on the degree of detail to be incorporated into the final result. The following parts of the single file of the BIM model were distinguished:

(b) Base Model: in charge of modeling the infrastructure skeleton. In this phase, the recorded detail quality was low. The single BIM model file for this phase houses modeling based on common architectural elements, such as walls, floors, windows, or roofs.

(c) Detailed model: it considered specific elements that allowed the differentiation and identification of the infrastructure. In this phase, the BIM model file starts to house unique components, such as lockers, desks, projectors, pictures, or textures that were modeled in detail separately, and inserted to the file with the complete infrastructure model afterwards.

(d) Stage for data assignments to the model: was given 40-day duration and will take place simultaneously with the previous stage. A database is compiled using spreadsheets in which all the time-schedules of the 2019-2020 academic year are filled in for each of the two degrees and four masters. The database is compiled for each of the cited degrees and for each of the student groups and covers all the teaching offer in this School.

(e) Synchronization stage: this stage required the completion of the previous stages. Some possible occasional modifications or improvements could be made in the database, though continuous modifications in this stage would not be acceptable.

(f) Drafting stage: as in the previous stage, the wording and documentation of the Project is to be made after all preceding activities are finished, so that the results in terms of benefits and inconveniences of the modeling and methodology are incorporated.

As shown in Figure 3, the longest stages were the specific modeling and the data assignment stages due to the character of the infrastructure. With respect to stage simultaneity, the ones for data collection and assignment stand out. Contrarywise, the base model phases had a low simultaneity because subsequent activities are required. In addition, the synchronization stage had a low percentage 
of simultaneity. This was caused by the need of having a database structure and a set-up model in order to keep synchronization between model and data when a change is made.
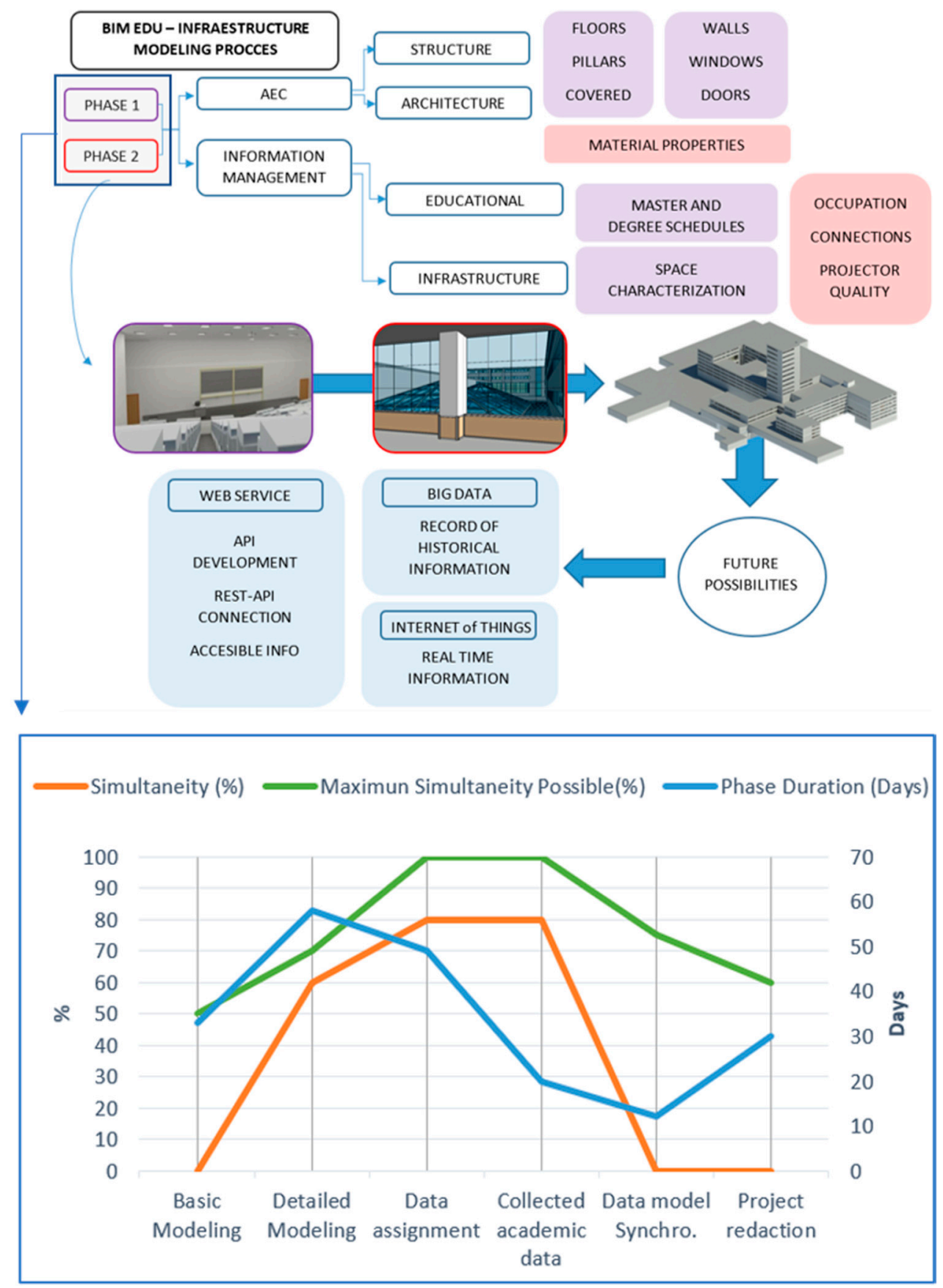

Figure 2. Modeling process and simultaneity.

The graph also shows both duration periods and task simultaneity referring to the project execution by a single person. This graph would show big changes depending on the number of professionals involved, thereby obtaining an optimum simultaneity curve where the objective consists of increasing the task simultaneity, improving the efficiency, and reducing total task time.

The efficiency increase can be exemplified in the base model stage. The simultaneity of the execution at this stage by a single person is zero. However, this simultaneity can still be increased by a large percentage by making task batches, that is, the base modeling could be divided into sub-stages, such as levels and grids, façade modeling, or door type modeling, all with the objective of 
creating independent tasks that allow simultaneous work of several persons and so reducing the total execution time.

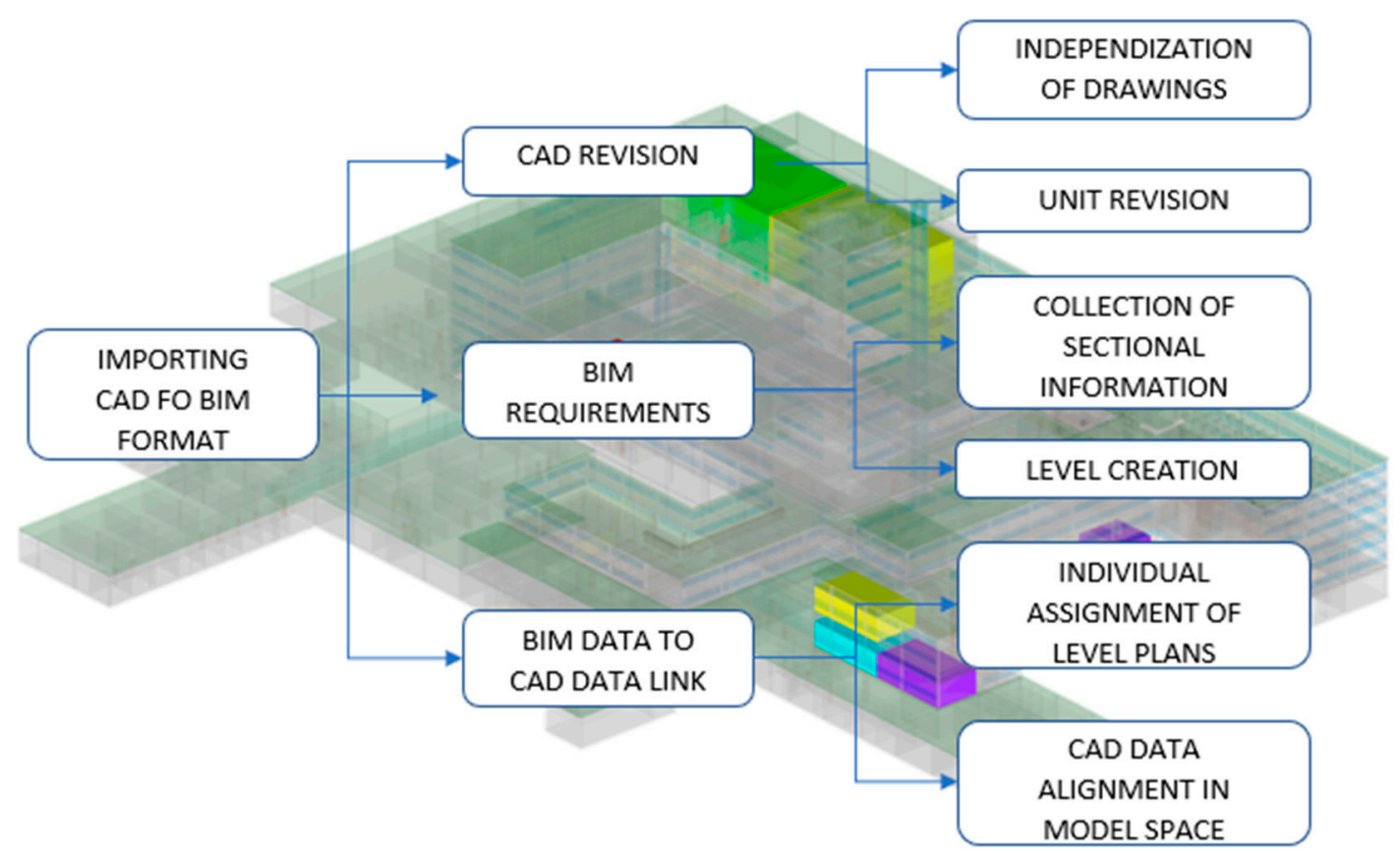

Figure 3. Flow chart.

\subsection{Starting Documentation}

The starting point of the modeling stage after the development of BEP is based on documentation in 2-D CAD format. The files did not have a specific date of expedition and possibly included elements that were not updated at the time of the model development. In turn, the received documentation consisted of plan drawings of the building floors at different levels but contained no section or elevation drawings nor aspects such as the floor height or the distance to the false ceilings. The option was to plot the geometry information and make in-place measurements of the missing data.

\subsection{CAD-BIM Linking}

With the existing and enhanced information, the modeling with BIM methodology started using BIM modeling Software. The modeling of different typologies of infrastructure not only differs in the construction typology but also in the used software and the workflow, which must be adapted according to the available tools. In this case, and with the described initial conditions, the option was to import files in $\mathrm{CAD}$ format referring to the plan views of ten different floor levels having previously preceded to the required drawing separation.

The used procedure and the methodology of execution are depicted in Figure 3. Firstly, a CAD data revision must be done searching for possible geometric infrastructure data omission or mistakes.

CAD and BIM software must be checked. Moreover, BIM software model demands independent $\mathrm{CAD}$ information at a high level thus a restructuring of CAD information was developed to achieve the correct insertion of CAD data into BIM environment.

Once CAD information was restructured, it was necessary to create an appropriate level in BIM environment. Moreover, CAD information available only referred to floor plant and sectional dimensions, and were taken in situ, to provide real height to BIM levels completing BIM requirements of Flow chart.

Relating BIM to CAD data link, it was necessary to insert each CAD information and align it according to geometric infrastructure properties individually. Once it has been done, the modeling phase starts. 


\section{Case Study}

In order to reach the main objectives of the case study shown in this paper, two main aspects were addressed. The first one was related to the infrastructure modeling and the development of the 3-D model of the ETSICCP. The second challenge was the implementation of the adequate tools for the management of the infrastructure through use of the BIM model of the building.

\subsection{Main Characteristics of the ETSICCP}

The total area modeled for the ETSICCP was $38,970.84 \mathrm{~m}^{2}$. Regarding the useful area, it was $32,631.23 \mathrm{~m}^{2}$. The most outstanding were 26 and 27 as shown in Table 1. ETSICCP is used by more than 4000 students of different degree levels: Graduate, Master, and Ph.D. These figures give the idea of the magnitude of the school facilities as well as the excellent opportunity of implementing new management approaches for spaces, maintenance equipment and the relation with the staff, being aware of the impact that can be generated by a BIM methodology implementation.

Table 1. Surface of teaching spaces.

\begin{tabular}{cccc}
\hline Name & Surface & Name & Surface \\
\hline José Echegaray Room & $69.61 \mathrm{~m}^{2}$ & Room 24 & $101.16 \mathrm{~m}^{2}$ \\
Room 1 & $238.88 \mathrm{~m}^{2}$ & Room 26 & $329.94 \mathrm{~m}^{2}$ \\
Room 2 & $115.08 \mathrm{~m}^{2}$ & Room 27 & $330.64 \mathrm{~m}^{2}$ \\
Room 3 & $117.68 \mathrm{~m}^{2}$ & Room 28 & $57.82 \mathrm{~m}^{2}$ \\
Room 4 & $238.87 \mathrm{~m}^{2}$ & Room 29 & $59.52 \mathrm{~m}^{2}$ \\
Room 5 & $57.82 \mathrm{~m}^{2}$ & Room 30 & $58.78 \mathrm{~m}^{2}$ \\
Room 6 & $59.52 \mathrm{~m}^{2}$ & Room 31 & $58.78 \mathrm{~m}^{2}$ \\
Room 7 & $58.78 \mathrm{~m}^{2}$ & Room 32 & $57.22 \mathrm{~m}^{2}$ \\
Room 8 & $58.78 \mathrm{~m}^{2}$ & Room 38 & $100.10 \mathrm{~m}^{2}$ \\
Room 9 & $57.22 \mathrm{~m}^{2}$ & Room 39 & $100.02 \mathrm{~m}^{2}$ \\
Room 11 & $54.90 \mathrm{~m}^{2}$ & Room 40 & $58.67 \mathrm{~m}^{2}$ \\
Room 12 & $56.39 \mathrm{~m}^{2}$ & Languages Room & $57.26 \mathrm{~m}^{2}$ \\
Room 13 & $56.39 \mathrm{~m}^{2}$ & Room 45 & $103.25 \mathrm{~m}^{2}$ \\
Room 14 & $56.39 \mathrm{~m}^{2}$ & Room 46 & $101.16 \mathrm{~m}^{2}$ \\
Room 15 & $56.39 \mathrm{~m}^{2}$ & Ag. Betancourt Room & $56.70 \mathrm{~m}^{2}$ \\
Room 16 & $56.39 \mathrm{~m}^{2}$ & CAD Room & $55.67 \mathrm{~m}^{2}$ \\
Room 17 & $56.39 \mathrm{~m}^{2}$ & Exam room & $1652.12 \mathrm{~m}^{2}$ \\
Room 18 & $56.39 \mathrm{~m}^{2}$ & Computers room & $90.56 \mathrm{~m}^{2}$ \\
Room 22 & $113.49 \mathrm{~m}^{2}$ & Turing Room & $121.18 \mathrm{~m}^{2}$ \\
Room 23 & $103.25 \mathrm{~m}^{2}$ & Total & $5289.32 \mathrm{~m}^{2}$ \\
\hline
\end{tabular}

Table 1 shows the useful area of all the classrooms, with a total surface of $5,289.329 \mathrm{~m}^{2}$. The table was originated from the BIM model by making a constant relationship between the model and either a spreadsheet or any SQL database, so that any information in the model can be reflected instantly in the database and vice-versa.

\subsection{The Information Model of the ETSICCP}

\subsubsection{Internal and External Modeling}

Thanks to the starting documentation and its adaptation to the new software, the modeling of each level could be carried out independently, starting with the floor system modeling and proceeding with the internal and external partitions modeling associated with each level. This phase was of great importance due to the geometrical character that the wall components give to the infrastructure. Internal and external, or façade, walls determine the skeleton of the internal and external infrastructure affecting the multiple component properties required by the space management. 
In view of the possibilities of using the model by the School staff for its own management based on BIM technology, the modeling followed the guidelines established by the developed BEP, thereby allowing for a context and management standards. As a matter of example, Table 2 shows the naming of various types of components in the model.

Table 2. Extract of BIM Execution Plan (BEP) nomenclature.

\begin{tabular}{cc}
\hline \multicolumn{2}{c}{ COMPONENTS } \\
\hline NAME OF THE COMPONENT & NAME OF THE VIEW \\
\hline WALL & A_Wall Thickness and Units \\
CURTAIN WALL & A_Courtain and location \\
CURTAIN WALL PANEL & A_Panel material \\
PILLARS & A_Pillar dimension A $\times$ dimension B \\
DOORS & A_Door and location \\
FALSE CEILINGS & A_FT and location \\
WINDOWS & Dimension A $\times$ Dimension B and units \\
REST OF THE OBJECTS & BIM software name by default \\
\hline
\end{tabular}

The modeling of the objects associated to each of the floor systems, as well as internal and external walls, was included in the base modeling stage described above with a very low percentage of simultaneity with respect to other stages. The required engagement for developing this stage was of great relevance for the whole Project.

The involved objects included in this base model contained some peculiarities that must be recognized, mainly in the modeling of walls. As commented in previous sections, the modeling was organized level by level and this procedure was of critical importance due to the particularities of the "wall" components. The initial temptation is to model walls, especially façades, considering the total height that a façade wall creates as beginning at level 0 and ending at level 3. Modeling with this methodology will lead to errors in terms of material measurements at a level. The origin of this error is the BIM software for wall accounting, that is, if a reform is intended partially affecting to level 2 of the infrastructure, the wall starting at level 1 through level 3 will not be accounted for. In order to have it accounted for by the software, the modeling must be organized level by level, which means having the façade modeled in several walls, one from level 0 to level 1, next from level 1 to level 2, and a third one from level 2 to level 3. In this way, the accounting will be exact, independently of the level at which the data is filtered.

With the objective of supplying the university with a model that can be used not only for space management but also for budgeting future reforms or changes in the infrastructure, modeling has been done according to the described methodology to avoid the cited errors. This is of key importance, as shown in the following case, where the error in quantities and budget of a partial reform in the ETSICCP was shown. The reform is supposed to affect only the first floor, which is level 1 . The rehabilitation of the corridors close to classrooms 26 and 27, as shown in Figure 4, is intended. Shaded in blue in Figure 3, the walls affected by this reform are highlighted. In terms of location, the affected wall is similar in level 0 and level 1, having an end in level 2, so that if the wall has been modeled from level 0 through level 2, wrong modeling occurs, as is shown in Figure 5. When the data is filtered by the level and the acting zone, this wall will not be reflected in the quantities list. An example of quantities and budget with a wrong modeling is shown in Table 3. The unit price adopted for the reform is the one proposed by the official Price Generator of Madrid Community. 


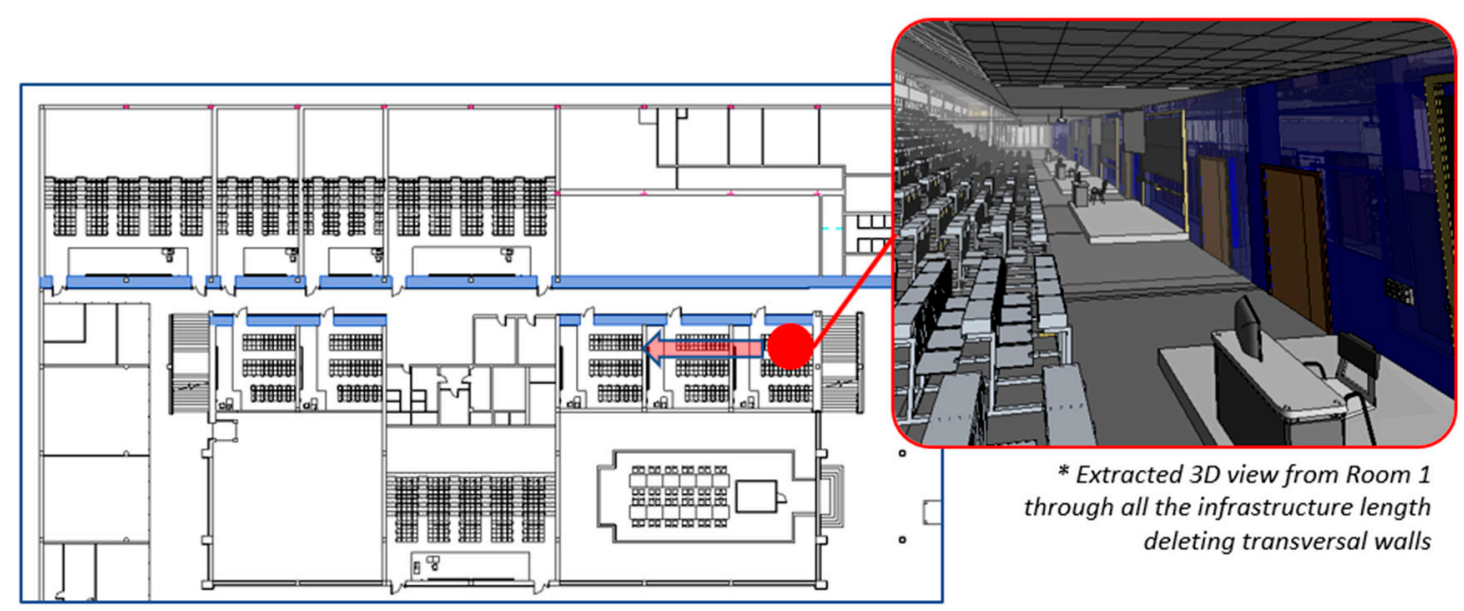

Figure 4. Corridor rehabilitation.

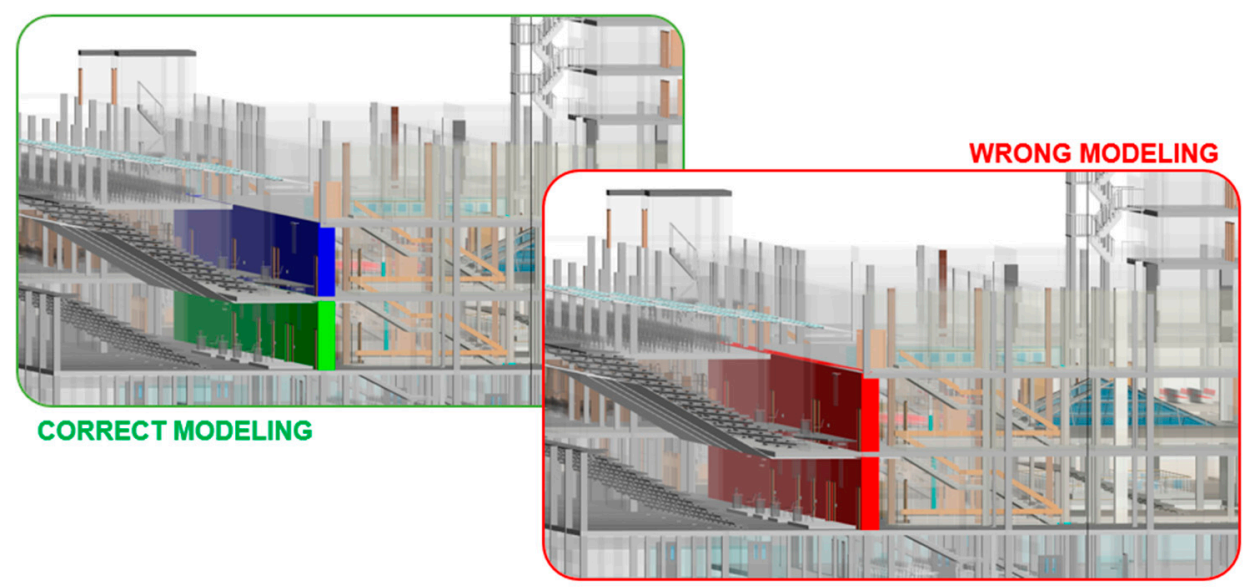

Figure 5. Correct and wrong wall modeling.

Table 3. Budget based on poor modeling.

\begin{tabular}{cccccc}
\hline Object & Area $\left(\mathbf{m}^{\mathbf{2}}\right)$ & Volume $\left(\mathbf{m}^{\mathbf{3}}\right)$ & Length $(\mathbf{m})$ & Rehabilitation Cost $\left(\boldsymbol{\epsilon} / \mathbf{m}^{\mathbf{2}}\right)$ & Total Cost $(\boldsymbol{\epsilon})$ \\
\hline Basic Wall & 35.05 & 14.02 & 23.8 & 45.81 & 1605.46 \\
Basic Wall & 22.00 & 22.00 & 5.0 & 45.81 & 1007.82 \\
Basic Wall & 20.42 & 4.08 & 4.5 & 45.81 & 935.26 \\
Basic Wall & 29.20 & 5.84 & 7.7 & 45.81 & 1337.65 \\
\hline
\end{tabular}

Thanks to the correct modeling in the above described way, the quantities and budget are substantially different, as it is shown in Table 4.

Table 4. Budget based on correct modeling.

\begin{tabular}{cccccc}
\hline Object & Area $\left.\mathbf{( m}^{\mathbf{2}}\right)$ & Volume $\mathbf{( m}^{\mathbf{3}} \mathbf{)}$ & Length $(\mathbf{m})$ & Rehabilitation Cost $\mathbf{( € / \mathbf { m } ^ { \mathbf { 2 } } )}$ & Total Cost $(\boldsymbol{\epsilon})$ \\
\hline Basic Wall & 35.05 & 14.02 & 23.8 & 45.81 & 1605.46 \\
Basic Wall & 22.00 & 22.00 & 5.0 & 45.81 & 1007.82 \\
Basic Wall & 20.42 & 4.08 & 4.5 & 45.81 & 935.26 \\
Basic Wall & 335.60 & 335.60 & 79.8 & 45.81 & $15,373.74$ \\
Basic Wall & 29.20 & 5.84 & 7.7 & 45.81 & 1337.65 \\
\hline
\end{tabular}

Comparing both modeling alternatives, the error affecting walls modeled in several levels can be clearly appreciated. This error can lead to significant cost differences, as shown in Figure 6. 


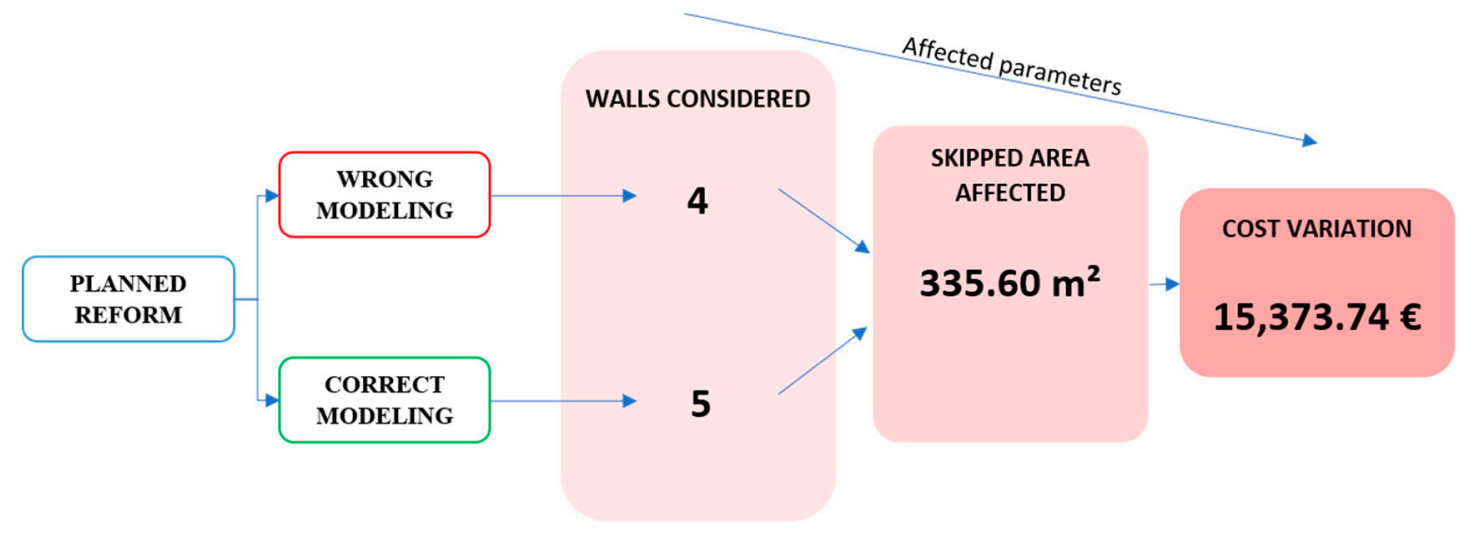

Figure 6. Parameters variations by modeling.

\subsubsection{Generation of Spaces}

This is a part of the stage for assigning data to the model. It features the works of basic modeling of the floor systems and internal walls. Before the beginning of this phase, the spaces already exist in the model. Nevertheless, they have no properties. Thanks to the room component created, the spaces were given characteristics, and it was possible to assign them some properties that will be fundamental for management.

There are multiple properties that can be attributed to the School spaces. Some of them, like area, volume, and location, referring to the floor level, are automatically created. This real information can be filtered and made exportable to databases.

There is the chance of manually expanding the assignment of data related according to the requirement of the teaching institution. Some examples of new parameters developed and incorporated to the model are:

(a) Department: to which the space belongs.

(b) UPM Code: alphanumeric character string that the UPM uses to register all the spaces owned by the University.

(c) Available connections: with this parameter the connections available to the classroom are assigned for teaching purposes. Some of the properties of this parameter are the existence of Computer USB ports, the type of computerized system, and version which are installed, computer available and its properties, type of video projector, etc.

(d) Classroom occupation: this parameter is used to control the actual occupancy of the space and can be modified according to the nature of the activity occurring in the space. It provides information on the available seat number for a conventional class or for examination purposes. The parameter can be assigned due to the introduction of the typical seat bench units of the School, shown in Figure 7. By making an independent object for this case it is possible to increase the control capacity of these elements and also assign properties to the seat benches, such as functional state or the above mentioned UPM code.

Thanks to these new parameter designs and their properties, it was possible to elaborate data sheets as the one shown in Figure 8, referring to each of the classrooms where the main properties are depicted. These data sheets will be very useful for the teaching personnel and for the management staff. As a matter of sample, a data sheet is shown. It is worth noting the linking of it with the model because any change in the BIM model will be instantly reflected in the affected data sheet. That information transference is made possible due to the use of spreadsheets connecting the BIM model and the data sheets. 


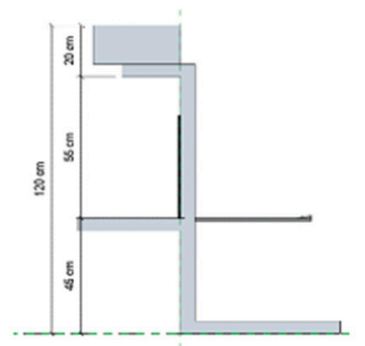

Side view with Units

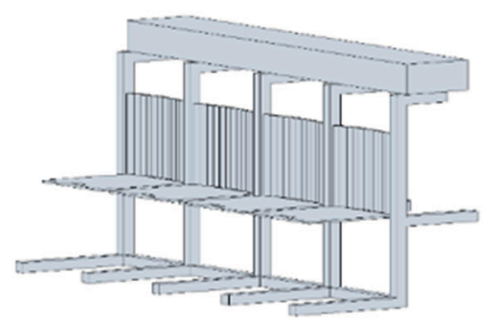

$3 D$ view

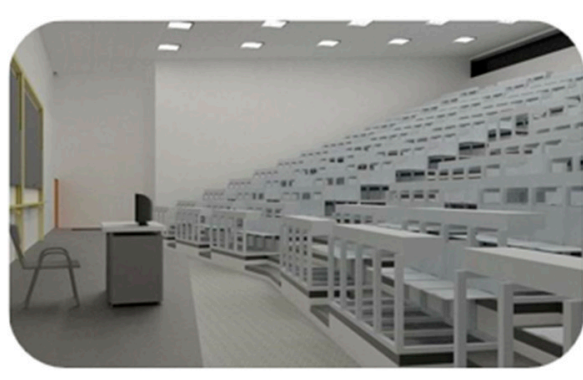

$3 D$ model view

Figure 7. Desk object developed.

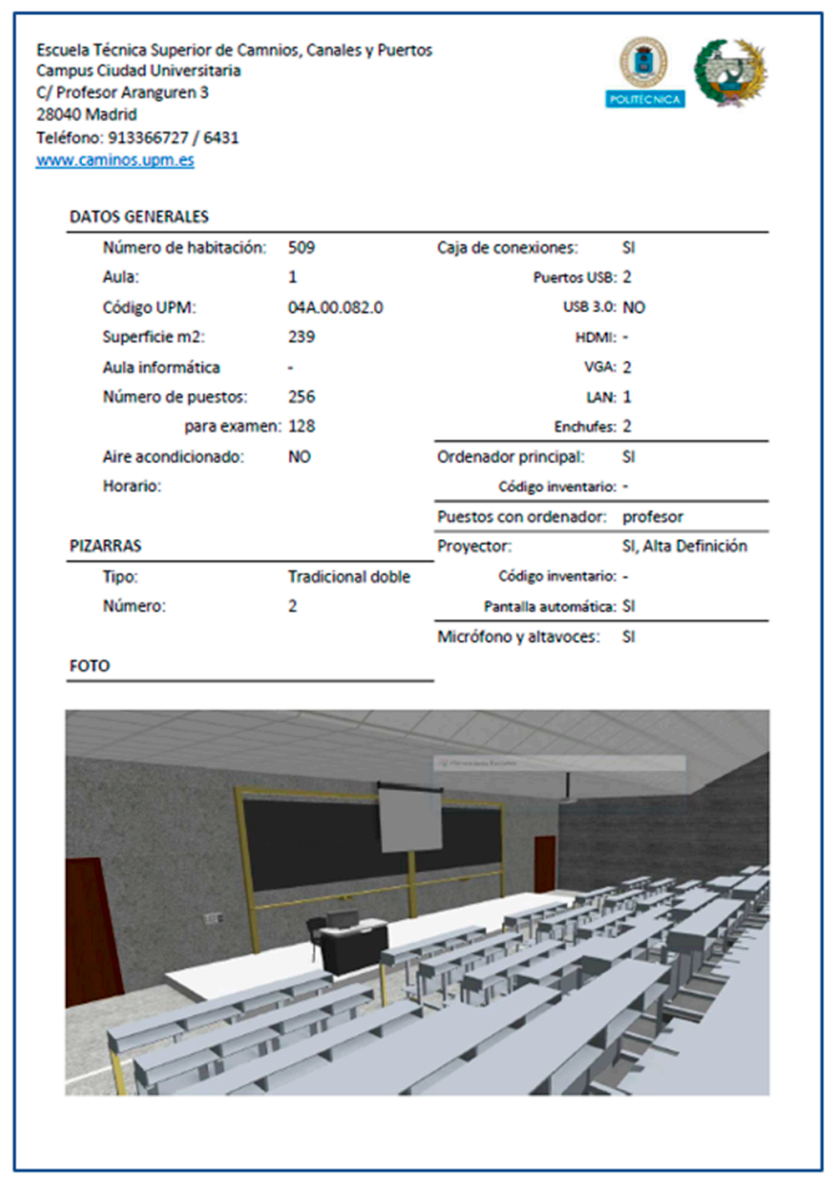

Figure 8. Room sheet.

\subsubsection{Modeling of Special Elements}

The modeling of this stage sometimes refers to very particular elements located in the infrastructure interior providing a greater precision considering the relevance of this outstanding part of the building above the pure space management.

Among the elements to be modeled in a very detailed way due to their singularity, Figure 9 shows that the roof of the School Library, the "noble zone" containing the main dependencies of the School and the big classrooms 26 and 27 stand out. 


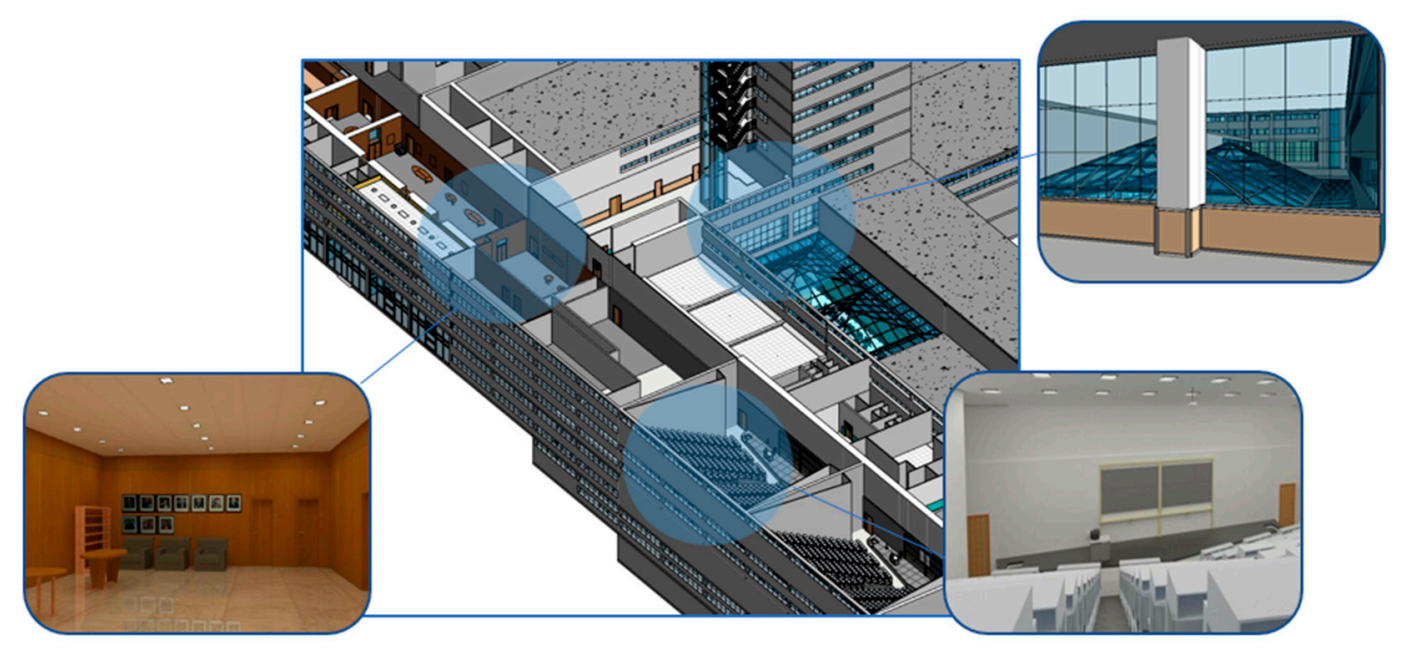

Figure 9. High detailed locations.

\subsection{BIM-Based Educational Management}

The development of a BIM-based FM methodology is based on a correct identification of the infrastructure real needs which in turn will depend on the service to be performed. This Project has an educational scope where an efficient management is very important. An educational infrastructure contains multiple variables that traditionally have been considered independently. In the manner that BIM has meant a breakthrough in terms of infrastructure design because it can unify and combine different disciplines in a single model, in the management field this situation is quite similar. Thanks to the creation of the BIM model it is possible to integrate the totality of the management systems normally used in the School in an independent way. This situation can be exemplified by the locker management and classroom occupation, normally managed in parallel without mutual connections. Thanks to the BIM model and the considerations assumed at the modeling stage it is possible to have a common management system based on the BIM model, by considering parameters which have never been considered before in independent management, for example, the proximity of the student locker to his classroom.

The developed model boasts the capacity of acquiring new properties and enhancing the model by hosting a greater amount of information that can even be much more specific, like the maintenance of the classroom projector, assigning parameters, such as the maintenance revision periods or detected incidences. The availability of the BIM model also provides the possibility of putting together the maintenance of the cleaning equipment and activities with the occupation periods of classrooms or other spaces subjected to timing usage or occasional events.

\subsubsection{Synchronization of BIM Model and Teaching Schedules}

The classroom occupation in the teaching time is the first goal of this Project for establishing a global management model based on BIM methodology. In turn, this methodology is based on the compilation of data for further selected assignment and visualization of information by the use of spreadsheets that allow linking with the BIM model by means of the Software Navisworks that has a total linking with the BIM software tool used for modeling.

The cited database contains a great deal of information due to the wide range of studies offered in the School infrastructure. The data reflects the classroom occupation for all groups and semesters of the following studies:

- Bachelor's Degree in Materials Engineering,

- Bachelor's Degree in Civil Engineering,

- Master's Degree in Materials Engineering, 
- Master's Degree in Civil Engineering (for professional capacity of Ingeniero de Caminos, Canales y Puertos in Spain),

- Master's Degree in Engineering Structures, Foundations and Materials, and

- Master's Degree in Civil Engineering Systems.

The hierarchical process for completing the final database to be synchronized is shown in the following diagram in Figure 10.

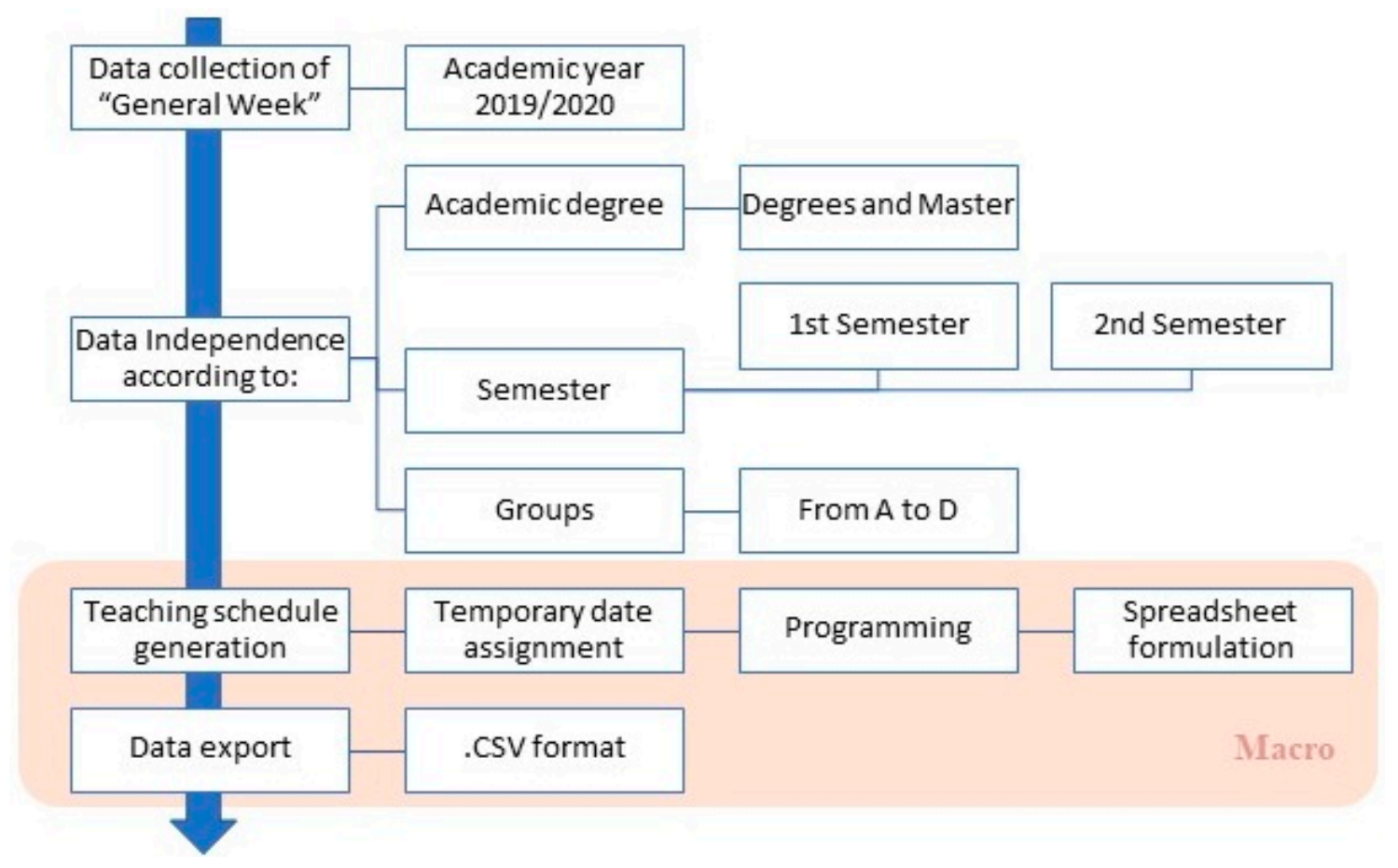

Figure 10. Collection and structure of educational data.

The process starts with the compilation of the time schedules as included in the Teaching Guidelines of the different offered studies. This time schedule called "General Week" reflects the timing for each day of the week generically, with no allusion to the exact date or the specific classroom.

Then the data is independently considered for each of the studies, semesters, and groups. This step is of vital importance due to the large volume of the final database. By separating the information, the chance of error is less and it increases the chance of quick detection of possible inconveniences when trying to synchronize the data with the model.

The generation of the teaching calendar consists of giving a specific date to each of the subjects, that is, transforming the information structure from a generic weekday to a specific weekday. The volume of data in the spreadsheet referring to a generic timetable is only $6.8 \%$ of the final timetable with the total days of the week. The generation of this timetable is done with programming formulation included in the spreadsheet.

Finally, the exportation of the spreadsheets was realized by means of a Comma Separated Value (.CSV) format as required by the worksheet software used. In addition, a Macro routine is developed in order to automatize the process of semester generation and data exportation and make the updating process by the School staff easier. The aspects contemplated in the Macro are orange-shaded in the above diagram.

Thanks to the existence of the cited database, it is possible to extract precise data. This can be seen in Figure 11, where the timetable required for the first academic year is shown. This data can be synchronized with the BIM model, and, in this way, it is possible to graphically show the location of the different teaching hours for each grade. Additionally, the possible connection of IoT with the model 
allows the incorporation of real-time information and gives a permanent updating of the database. IoT in BIM entails real time data information. The data flow starts from IP video cameras, counting entrances and exits of people from each room, as well as reporting humidity and temperature, by sending the captured data to the SQL database, which is in constant synchronization with the BIM model.

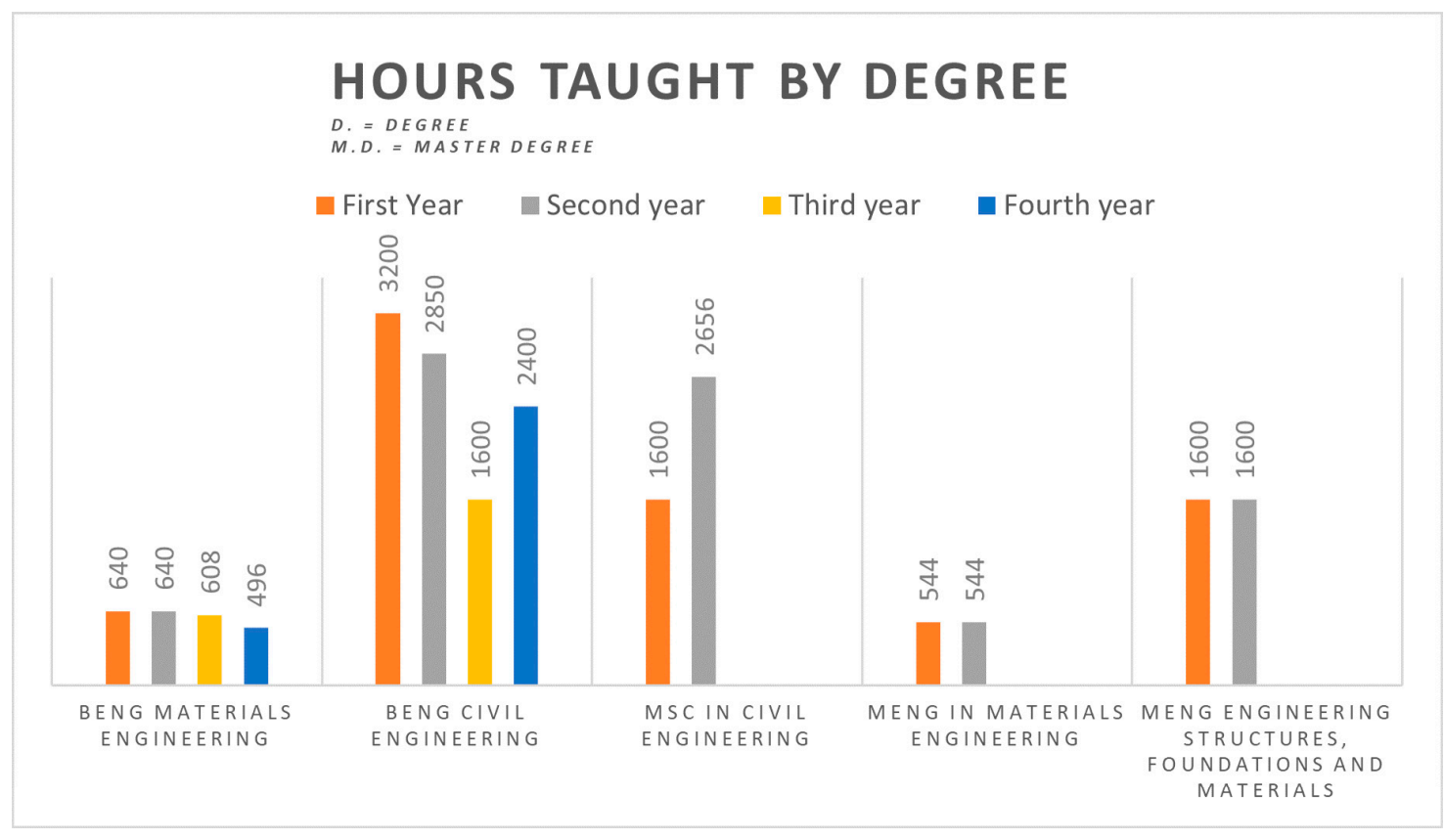

Figure 11. Hours taught by degree.

With all databases available in terms of use, the linking of the information with the BIM model can be carried out. The linking unit between the database and the model is the name of the spaces, that is, the classroom name. It is of key importance to succeed with the linking to have identical identification words of the classrooms in the database and in the BIM model. This way the automatic linking is obtained for each task, that is, for each class with the corresponding room identification and location in the model, thanks to the classroom name. For the described synchronization process in this paper, teaching schedule was considered. Thus, it must be considered that the synchronization process was variable depending on the information required to be synchronized with the BIM model.

The incorporation of the teaching calendar can result in a Gantt Diagram, in which each activity means a given lesson, shown in Figure 12. It is worth noting that the origin of Gantt Diagrams is for construction activities which normally have a duration of days. In our case, the class duration is a few hours maximum and this makes the Gantt Diagram very long in comparison to the ones normally used in construction works.

The structure used in the teaching visualization of the model is made by establishing shades of different colors depending on the offered grades, the visualization is shown in Figure 12. Of course, these criteria can be modified depending on the future needs of the School.

\subsubsection{Synchronization of the Lockers}

The management of an educational infrastructure encompasses various aspects in addition to classroom management. The physical properties of this building characterized by its large extension makes it even more important to have one efficient and complete management beyond the pure educational aspects. The school has several cleaning teams, some of them working in the evening and some at night, as well as maintenance personnel for computer equipment and for mechanical and electrical equipment of heating and air conditioning, among others. The enriching of the model and the incorporation of assigned information over time will continue to develop different management 
methodologies. This Project, in addition to setting-up some criteria for classrooms, also includes a specific system for locker management, as is shown in Figure 13.

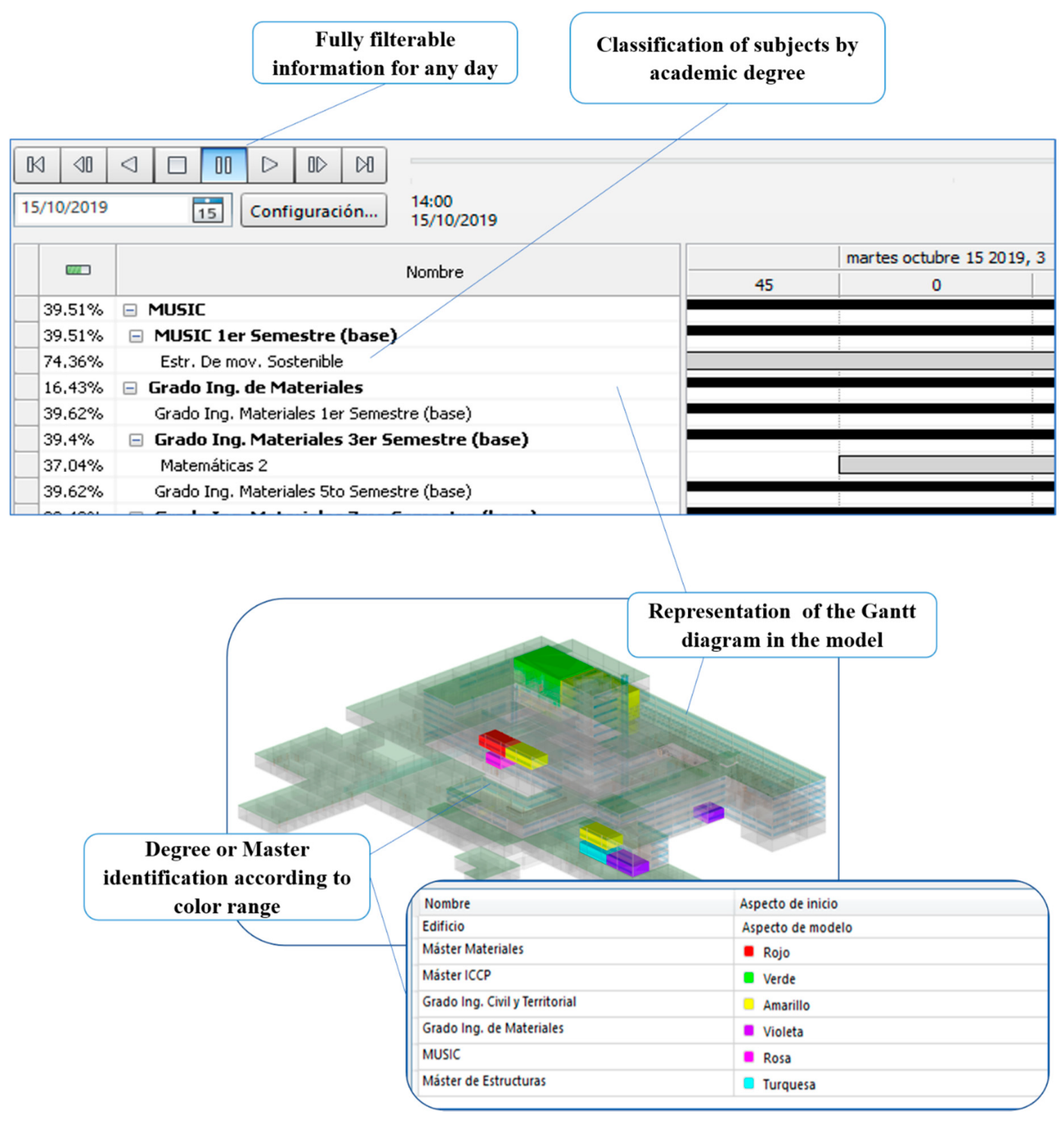

Figure 12. BIM educational data visualization.

The methodology proposed for the locker management of the infrastructure is based on the linking in real time between a database consisting of spreadsheets and a BIM model. By this methodology, a student register is made for a specific locker, and the model would recognize the student particularities and retrieve the information about the locker positioning or distance to the student classroom.

The communication process between the database and the BIM model is exemplified in Figure 13.

The process starts with the generation of some parameters in the BIM model, and then they are assigned to the corresponding objects. In this case, study the parameters are the ones referring to the locker owner, the rental period, and the student register and Identity Card. The naming at both sides, that is, in both the model and the database, must be identical; otherwise, the system will not be able to show the information included in the database. 


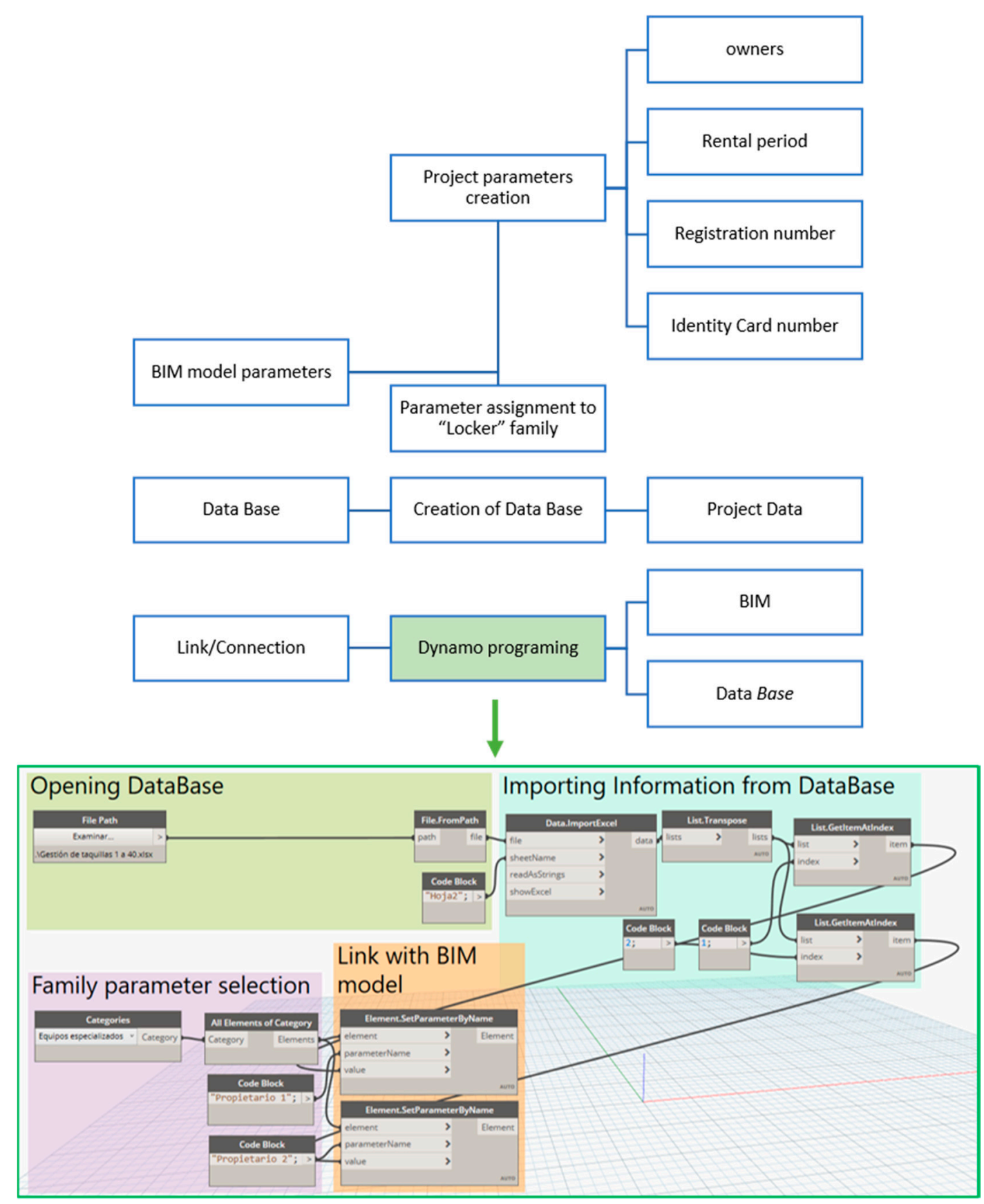

Figure 13. Dynamo lockers parameters programming.

The linking in real time of the database and the BIM model is achieved by means of Dynamo programming that allows the possibility of detecting the database, reading the information and assigning it to the pertinent object. The communication is bi-directional so that the modifications made in the model are automatically reflected in the database, and vice-versa. Dynamo permitted the synchronization of the locker information in datasheets with the model. Some further programming by means of $\mathrm{C \#}$ and python was performed in order to synchronize other features of the model.

The original idea of the locker management is based on the filling of the database by the competent staff personnel of the school but there are modifications leading to a higher efficiency of the system thanks to the database used. The spreadsheet used for the locker registration can be connected to a web environment accessible to all students, thereby allowing on-line registration that is in real time and instantly reflected in the BIM model. 


\subsubsection{3-D Scanning}

Scanning technology applications are commonly applied in BIM methodologies, mainly in the existing infrastructure management. As is mentioned in present and future developments of BIM point of this paper, 3-D Laser Scanning is the most common tool in terms of capturing data for BIM modeling purposes, thus the main applicable sector is for already existing infrastructure built with no BIM information providing owners and managers with a building BIM model.

The application of 3-D Scanning technology is not conventional for this developed project of the ETSICCP. While the Scanning should have been implemented before the modeling phase in order to obtain a cloud of points as a modeling base, the BIM ETSICCP took CAD information as the first stone for the BIM model. 3-D scanning was developed when an advanced BIM model of the building was already created, the incorporation of this technology provides the project with very interesting upgrades. One of them is the creation of the cloud of point allowing us to restructure BIM model and the possibility of correcting any geometric error.

The 3-D Laser Scanning developed in this project was provided by Leica company which provides not only the fact of creating a cloud of points but also the possibility of implementing real photos to said cloud, creating a full virtual navigable environment. Pictures of internal data capture and points of cloud are attached as Figures 14 and 15.

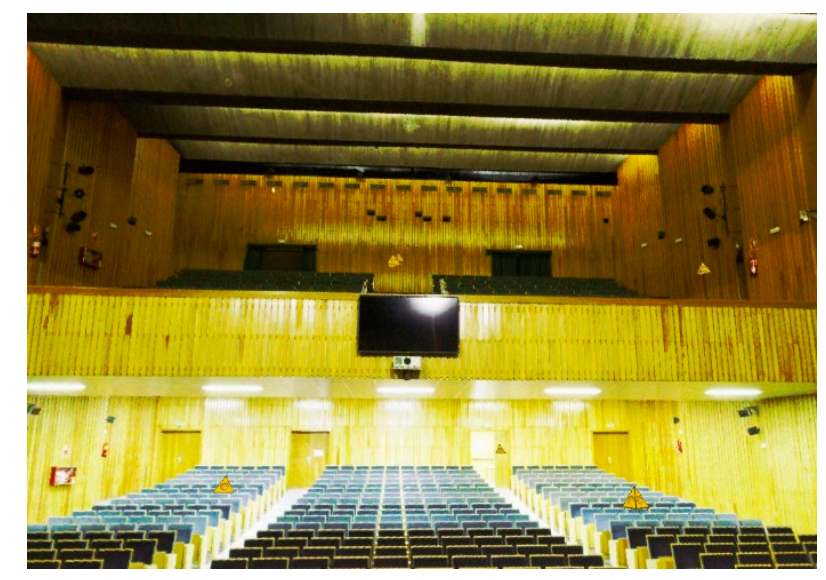

Figure 14. Internal data capture of the assembly hall of Civil Engineering School (ETSICCP) at Universidad Politécnica de Madrid (UPM).

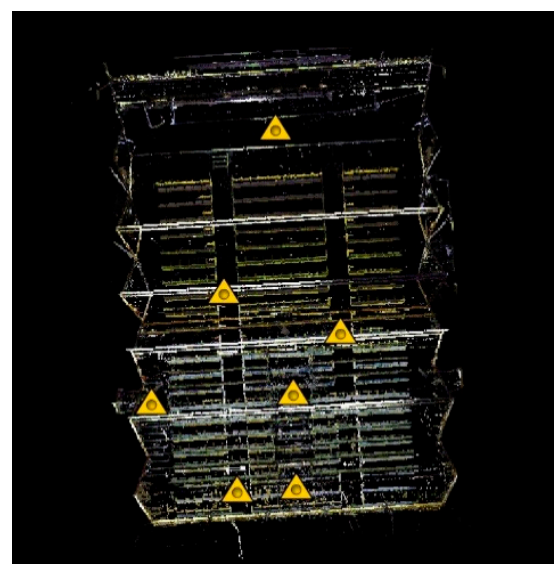

Figure 15. Cloud of point of the assembly hall of ETSICCP.

Leica systems provide an adjustable cloud of points. For this project, the cloud was upgraded with real UTM coordinates taken by the Topography department of the ETSICCP. Once UTM coordinates are 
registered, the UTM coordinate is assigned to different points of the cloud, and the Leica software system automatically autocorrects the position of the total cloud of points, locating all the infrastructure in a real placement. With this implementation, we open the path of incorporating the ETSICCP infrastructure to developed technologies, like Google maps, joining street view with internal infrastructure paths.

\section{Discussion}

Public institutions make efforts to improve the quality and efficiency of their management. Even traditional techniques based on paper formats are used in many cases. Little improvements implementing technologies, such as identification systems or real time data, have been carried out in the previous years. This BIM-FM system is available and accessible for all infrastructure staff and users. A single management system allows managing rooms, equipment, or climatic conditions. It should be mentioned that the sensors to monitor temperature, humidity and occupation are not still placed in all the rooms, though the BIM-FM has been designed to do so and supports this possibility. This has been achieved and checked through prototypes and the overall implementation depend on future investments of the university. BIM-FM has also solved other problems, such as the interoperability, accessibility, integrity, and high initial investments. This integral solution goes one step beyond the current management techniques.

Smart campus is a general concept, without a single process to reach it. The methodology adopted by this project entailed the BIM implementation. This showed several pros and cons that are discussed in this section.

The paper gathers the first steps of applying several emerging technologies in order to achieve the smart campus category. These steps are the final phase of a process that transforms a traditional campus into an intelligent one. The process has three stages: traditional campus, e-campus, and digital campus as the final phase [86].

The starting point of the project, and according to literature review, is the traditional Campus management systems. Later, in the third phase, the project considers technologies, such as IoT [86-89,94,96,97], RFID [86,89-95], or sensor applications [88,89,95,97-99]. However, the implementation of BIM, together with the mentioned technologies, could notably improve the profits related to other technologies, such as energy management [88], reductions of electricity costs [89], management of university assets [89], or provide an information map of the campus for location purposes [89].

Considering BIM as a virtual representation of all the elements of the infrastructure throughout their lifecycle or BIM as a central point of information storage [3,5-7] and through synchronization with other technologies, it could reach an advanced smart campus concept.

IoT or sensor implementation without BIM may provide real-time information in different databases formats. However, IoT and sensors, together with BIM-FM, can be synchronized and provide real-time information not only in database formats but can also reflect all the information to each infrastructure element providing the user with a total visualization. Real-time occupation in this project is registered by sensors and the data is sent to a SQL database. With the BIM-FM methodology, the institution offers the users a range of colors applied to a floor plan to easily locate this real-time occupation.

Managing the university assets by RFID is one of the most common practices in the university environment. However, the proposal of this study was to manage the university assets through the BIM model, showing remarkable benefits. In this case, all assets are located and boast detailed geometry and special characteristics. Moreover, the visualization of the environment, allowed by the model, simplifies the use of the tool. This permits interaction with all the infrastructure elements and characteristics or the parameters could be consulted.

Additionally, BIM-FM implementation is a complex process that demands the virtual construction of a BIM model. Moreover, BIM information formats attach multiple problems in terms of interoperability and the sector demands international standards, such as the Construction Operations Building Information Exchange (COBIE) standard [3]. Other challenges and drawbacks of the BIM-FM 
implementation are the legal issues related to responsibilities or confidential information in the total collaborative environment established in BIM [102,103].

\section{Conclusions}

This project developed a new BIM-based FM system for ETSICCP. As a result of the research, a complete BIM model was performed, hosting all the parameters associated with day-to-day management tasks. The BIM-FM system enables the management of classrooms, sport facilities, locker assignment, or any location information. This management encompasses the possibility of making reservations, placing academic scheduling, reading temperature and humidity, reveal sitting capacity, or showing equipment maintenance. For that purpose, new software was developed, allowing the interaction of the BIM model, through use of sensors and SQL databases. Both the model and its management software are hosted in a public server with total accessibility through an internet web page. The BIM-FM system supports the possibility to update real-time information from sensors that can monitor temperature, humidity, occupation, and any other information that sensors may provide in the future.

The development of this project under the BIM-EDU concept opens up the research path on BIM-based educational management holding concepts related to either pure infrastructure management or to educational terms. Moreover, implementing a new detailed BIM management system involves many challenges in order to achieve the completion with total success. Both the Social implementation process which deals with barriers, such as lack of software skills, and the resistance of changing work traditional methodologies stand out. In this sense, the main purpose of this research was to make the BIM management benefits accessible for all entities involved within the infrastructure management, even without any BIM skills.

As a result of the project, BIM model has been developed considering open mind properties in terms of adding new outstanding technologies, such as Big Data and IoT. Synchronizing real time data with a 3-D model of the infrastructure, as well as the possibility of saving historical information into a Big database, are the main targets of the project. A huge amount of data to be managed could be expected not only given the large size of the infrastructure but also given those real-time information demands. In that regard, spreadsheets as a database management were not considered efficient enough. Therefore, Big Data technologies, like SQL databases, were used because they allow this possibility.

However, not only social barriers have been found, but programming aspects related to file formats have also been detected. Furthermore, BIM modeling software boasts many peculiarities in terms of object properties that could directly affect the extracted data.

Overcoming those social and computer science challenges could be possible, thanks to BIM modeling, making the management of educational infrastructure much more efficient. Those detailed facts are quite common in the literature review for this project. A specific review for BIM environment is attached to the paper. Starting with standard definitions and applications of BIM provided by published research and expanding into the pure management BIM concept and new technologies synchronized with BIM, such as IoT and GIS.

Overall, literature review and research experience have many common points related to barriers for BIM implementation. Once those barriers were overcome, BIM management system provides a highly efficient operation and a more productive information flow for all the members associated with the infrastructure handling, especially in complex buildings, like university venues. Moreover, future developments, such as management protocols against COVID-19, could be implemented. Thanks to the new management tools, management staff could handle all spaces and internal movements, thanks to BIM model and BIG DATA databases.

In this study, BIM-FM was applied in new and broader ways for educational management, showing multiple benefits for future applications. Collecting and registering information in digital format is one of the most important gains attained, making the information for users or management staff more accessible. Another outstanding advantage is providing the ETSICCP with the BIM model. 
As a living organism where live scheduling information is given graphically, the model provides a great number of possibilities. This allows the management staff to manage the availability of a wide amount of spaces along the building or the cleaning protocols in a more efficient way. The large amount of detail in the model of the elements and parameters, i.e., connection box, capacity, air conditioning, or projector characteristics, which are detailed for each space and official documents attached to the website allow the lecturers to select the optimal space considering significantly more variables than with the traditional methods. Moreover, with the current COVID situation, digital and real time information can be of greater significance than in previous circumstances. BIM model, as the key point of the management methodology, provides detailed geometric information and allows the user to show real time data in a graphical way. Reducing the use of paper format, tracking down energetic consumption, and online FM were the outstanding points detailed for the management staff. It is important to highlight that a BIM methodology implementation demands training in BIM and software skills for the staff and the rest of the users. However, in this study, a total accessible internet webpage hosts all BIM information. Thus, no training is required. This turns the proposed methodology into the first BIM methodology with total accessibility and with the minimum social barriers related to its implementation.

Author Contributions: Conceptualization, M.G.A. and A.A.A.A.; Data curation, R.M.P. and A.A.A.A.; Formal analysis, R.M.P. and M.G.A.; Funding acquisition, M.G.A. and A.A.A.A.; Investigation, R.M.P., A.A.A.A. and M.G.A.; Methodology, M.G.A.; Project administration, M.G.A. and A.A.A.A.; Resources, M.G.A. and A.A.A.A.; Software, R.M.P. and A.A.A.A.; Supervision, M.G.A.; Validation, M.G.A.; Visualization, R.M.P.; Writing—original draft, R.M.P. and A.A.A.A.; Writing-review \& editing, M.G.A. All authors have read and agreed to the published version of the manuscript.

Funding: The APC was funded by the UPM through the Educational Innovation Project IE1920.0409.

Acknowledgments: The authors gratefully acknowledge the financial support provided by the Ministry of Economy, Industry and Competitiveness of Spain by means of the Research Fund Project PID2019-108978RB-C31. They also offer their gratitude to the "Colegio de Ingenieros de Caminos, Canales y Puertos" by awarding this Final Master Thesis as the most innovative project in the national contest of 2019. Authors also acknowledge the support provided by the UPM through the Educational Innovation Project IE1920.0409, as well as the support of the Leadership Team of the ETSICCP.

Conflicts of Interest: The authors declare no conflict of interest.

\section{References}

1. Liu, X.; Eybpoosh, M.; Akinci, B. Developing as-built building information model using construction process history captured by a laser scanner and a camera. In Proceedings of the Construction Research Congress 2012: Construction Challenges in a Flat World, West Lafayette, IN, USA, 21-23 May 2012; pp. 1232-1241.

2. Akbarnezhad, A.; Ong, K.C.G.; Chandra, L.R. Economic and environmental assessment of deconstruction strategies using building information modeling. Autom. Constr. 2014, 37, 131-144. [CrossRef]

3. Wang, X. BIM Handbook: A guide to Building Information Modeling for owners, managers, designers, engineers and contractors. Constr. Econ. Build. 2012, 12, 101-102. [CrossRef]

4. Tang, P.; Huber, D.; Akinci, B.; Lipman, R.; Lytle, A. Automatic reconstruction of as-built building information models from laser-scanned point clouds: A review of related techniques. Autom. Constr. 2010, 19, 829-843. [CrossRef]

5. Watson, A. Digital buildings-Challenges and opportunities. Adv. Eng. Inform. 2011, 25, 573-581. [CrossRef]

6. Redmond, A.; Hore, A.; Alshawi, M.; West, R. Exploring how information exchanges can be enhanced through Cloud BIM. Autom. Constr. 2012, 24, 175-183. [CrossRef]

7. Donath, D. Bauaufnahme und Planung im Bestand; Vieweg+Teubner: Wiesbaden, Germany, 2009.

8. Costin, A.; Adibfar, A.; Hu, H.; Chen, S.S. Building Information Modeling (BIM) for transportation infrastructure-Literature review, applications, challenges, and recommendations. Autom. Constr. 2018, 94, 257-281. [CrossRef]

9. MacLeamy, P. MacLeamy Curve Time/Schedule. In Collaboration, Integrated Information, and the Project Lifecycle in Building Design, Construction and Operation; Construction Users Roundtable (CURT): Cincinnati, OH, USA, 2004. 
10. Dave, B.; Buda, A.; Nurminen, A.; Främling, K. A framework for integrating BIM and IoT through open standards. Autom. Constr. 2018, 95, 35-45. [CrossRef]

11. Dave, B.; Kubler, S.; Främling, K.; Koskela, L. Opportunities for enhanced lean construction management using Internet of Things standards. Autom. Constr. 2016, 61, 86-97. [CrossRef]

12. Teizer, J.; Wolf, M.; Golovina, O.; Perschewski, M.; Propach, M.; Neges, M.; König, M. Internet of Things (IoT) for integrating environmental and localization data in Building Information Modeling (BIM). In Proceedings of the 34th International Symposium on Automation and Robotics in Construction (ISARC 2017), Taipei, Taiwan, 28 June-1 July 2017; pp. 603-609.

13. Adamkó, A.; Kádek, T.; Kósa, M. Intelligent and adaptive services for a smart campus. In Proceedings of the 5th IEEE International Conference on Cognitive Infocommunications, Vietri sul Mare, Italy, 5-7 November 2014; pp. 505-509.

14. Gray, M.; Gray, J.; Teo, M.; Chi, S.; Cheung, F. Building Information Modelling: An international survey. In Proceedings of the 19th International CIB World Building Congress, Brisbane, Australia, 5-9 May 2013; pp. 5-9.

15. Gu, N.; London, K. Understanding and facilitating BIM adoption in the AEC industry. Autom. Constr. 2010, 19, 988-999. [CrossRef]

16. Cerovsek, T. A review and outlook for a "Building Information Model” (BIM): A multi-standpoint framework for technological development. Adv. Eng. Inform. 2011, 25, 224-244. [CrossRef]

17. Wong, J.; Yang, J. Research and application of Building Information Modelling (BIM) in the Architecture, Engineering and Construction (AEC) industry: A review and direction for future research. In Proceedings of the 6th International Conference on Innovation in Architecture, Engineering and Construction (AEC), Loughborough, UK, 9-11 June 2010; pp. 356-365.

18. Rezgui, Y.; Beach, T.; Rana, O. A governance approach for BIM management across lifecycle and supply chains using mixed-modes of information delivery. J. Civ. Eng. Manag. 2013, 19, 239-258. [CrossRef]

19. Becerik-Gerber, B.; Jazizadeh, F.; Li, N.; Calis, G. Application areas and data requirements for BIM-enabled facilities management. J. Constr. Eng. Manag. 2012, 138, 431-442. [CrossRef]

20. Arayici, Y. Towards building information modelling for existing structures. Struct. Surv. 2008, 26, $210-222$. [CrossRef]

21. Akcamete, A.; Akinci, B.; Garrett, J.H. Potential utilization of building information models for planning maintenance activities. In Proceedings of the 13th International Conference on Computing in Civil and Building Engineering (ICCCBE 2010), Nottingham, UK, 30 June-2 July 2010.

22. Bae, A.; Lee, D.; Park, B. Building information modeling utilization for optimizing milling quantity and hot mix asphalt pavement overlay quality. Can. J. Civ. Eng. 2016, 43, 886-896. [CrossRef]

23. Chong, H.Y.; Lopez, R.; Wang, J.; Wang, X.; Zhao, Z. Comparative analysis on the adoption and use of BIM in road infrastructure projects. J. Manag. Eng. 2016, 32, 05016021. [CrossRef]

24. Kim, J.U.; Kim, Y.J.; Ok, H.; Yang, S.H. A study on the status of infrastructure BIM and BIM library development. In Proceedings of the 2015 International Conference on Computational Science and Computational Intelligence, Las Vegas, NV, USA, 7-9 December 2015; pp. 857-858.

25. Organization and Digitization of Information about Buildings and Civil Engineering Works, Including Building Information Modelling (bim)_Information Management Using Building Information Modelling. Part I: Concepts and Principles; UNE ISO 19650-1; International Organization for Standardization (ISO): Geneva, Switzerland, 2020.

26. Organization and Digitization of Information about Buildings and Civil Engineering Works, Including Building Information Modelling (BIM)_Information Management Using Building Information Modelling. Part II: Asset Development Phase; UNE ISO 19650-2; International Organization for Standardization (ISO): Geneva, Switzerland, 2019.

27. Boukamp, F.; Akinci, B. Automated processing of construction specifications to support inspection and quality control. Autom. Constr. 2007, 17, 90-106. [CrossRef]

28. Akinci, B.; Boukamp, F.; Gordon, C.; Huber, D.; Lyons, C.; Park, K. A formalism for utilization of sensor systems and integrated project models for active construction quality control. Autom. Constr. 2006, 15, 124-138. [CrossRef]

29. Cho, Y.K.; Alaskar, S.; Bode, T.A. BIM-integrated sustainable material and renewable energy simulation. In Proceedings of the Construction Research Congress 2010: Innovation for Reshaping Construction Practice, Banff, AB, Canada, 8-10 May 2010; pp. 288-297. 
30. Anjomshoaa, A. Blending building information with smart city data. In S4SC'14: Proceedings of the Fifth International Conference on Semantics for Smarter Cities; CEUR-WS.org: Aachen, Germany, 2014.

31. Döllner, J.; Hagedorn, B. Integrating urban GIS, CAD, and BIM data by service-based virtual 3D city models. In Urban and Regional Data Management-UDMS Annual 2007; Taylor \& Francis: Milton Park, UK, 2008; pp. 157-170.

32. Aziz, Z.; Riaz, Z.; Arslan, M. Leveraging BIM and Big Data to deliver well maintained highways. Facilities 2017, 35, 818-832. [CrossRef]

33. Nguyen, H.T. Integration of BIM and IoT to improve the building performance for occupants' perspective. J. 3D Inf. Model. 2016, 1, 100. [CrossRef]

34. McGibney, A.; Rea, S.; Ploennigs, J. Open BMS-IoT driven architecture for the internet of buildings. In Proceedings of the IECON Proceedings (Industrial Electronics Conference), Florence, Italy, 24-27 October 2016; pp. 7071-7076.

35. Carrillo, E.; Benitez, V.; Mendoza, C.; Pacheco, J. IoT framework for smart buildings with cloud computing. In Proceedings of the 2015 IEEE 1st International Smart Cities Conference (ISC2 2015), Guadalajara, JA, Mexico, 25-28 October 2015.

36. Blackstock, M.; Lea, R. Toward interoperability in a web of things. In Proceedings of the UbiComp 2013 Adjunct-Adjunct Publication of the 2013 ACM Conference on Ubiquitous Computing, Zurich, Switzerland, 8-12 September 2013; pp. 1565-1574.

37. Framling, K.; Kubler, S.; Buda, A. Universal messaging standards for the IoT from a lifecycle management perspective. IEEE Internet Things J. 2014, 1, 319-327. [CrossRef]

38. Manning, R.; Messner, J.I. Case studies in BIM implementation for programming of healthcare facilities. Electron. J. Inf. Technol. Constr. 2008, 13, 446-457.

39. Davies, R.; Harty, C. Implementing "site BIM": A case study of ICT innovation on a large hospital project. Autom. Constr. 2013, 30, 15-24. [CrossRef]

40. Nicolle, C.; Cruz, C. Semantic Building Information Model and multimedia for facility management. In International Conference on Web Information Systems and Technologies; Lecture Notes in Business Information Processing; Springer: Berlin, Germany, 2011; Volume 75, pp. 14-29.

41. Sabol, L. Building Information modeling \& facility management. In Proceedings of the 29th IFMA's World Workplace Conference, Dallas, TX, USA, 15-17 October 2008.

42. Lucas, J.; Bulbul, T.; Thabet, W. An object-oriented model to support healthcare facility information management. Autom. Constr. 2013, 31, 281-291. [CrossRef]

43. Wang, Y.; Wang, X.; Wang, J.; Yung, P.; Jun, G. Engagement of facilities management in design stage through BIM: Framework and a case study. Adv. Civ. Eng. 2013, 2013. [CrossRef]

44. Valero, E.; Adan, A.; Huber, D.; Cerrada, C. Detection, modeling and classification of moldings for automated reverse engineering of buildings from 3D data. In Proceedings of the 28th International Symposium on Automation and Robotics in Construction (ISARC 2011), Seoul, Korea, 29 June-2 July 2011; pp. 546-551.

45. Huber, D.; Akinci, B.; Adan, A.; Anil, E.B.; Okorn, B.; Xiong, X. Methods for automatically modeling and representing as-built building information models. In Proceedings of the NSF Engineering Research and Innovation Conference, Atlanta, GA, USA, 1 January 2011.

46. Xiong, X.; Huber, D. Using context to create semantic 3D models of indoor environments. In Proceedings of the British Machine Vision Conference (BMVC 2010), Aberystwyth, UK, 30 August-2 September 2010.

47. Xiong, X.; Adan, A.; Akinci, B.; Huber, D. Automatic creation of semantically rich 3D building models from laser scanner data. Autom. Constr. 2013, 31, 325-337. [CrossRef]

48. Hajian, H.; Becerik-Gerber, B. Scan to BIM: Factors affecting operational and computational errors and productivity loss. In Proceedings of the 27th International Symposium on Automation and Robotics in Construction (ISARC 2010), Bratislava, Slovakia, 25-27 June 2010; pp. 265-272.

49. Bhatla, A.; Choe, S.Y.; Fierro, O.; Leite, F. Evaluation of accuracy of as-built 3D modeling from photos taken by handheld digital cameras. Autom. Constr. 2012, 28, 116-127. [CrossRef]

50. Bernardini, F.; Rushmeier, H.; Martin, I.M.; Mittleman, J.; Taubin, G. Building a digital model of Michelangelo's Florentine Pieta. IEEE Comput. Graph. Appl. 2002, 22, 59-67. [CrossRef]

51. Reig, I.; Boquera, J.; Expresión, P.E.-E. Basílica de Nuestra Señora de los Desamparados. Reconstrucción gráfica: Levantamiento planimétrico. EGA Rev. Expresión Gráfica Arquit. 1999, 5, 168-173. 
52. Fontana, R.; Greco, M.; Materazzi, M.; Pampaloni, E.; Pezzati, L.; Rocchini, C.; Scopigno, R. Three-dimensional modelling of statues: The Minerva of Arezzo. J. Cult. Herit. 2002, 3, 325-331. [CrossRef]

53. Lorenzo, A.P. Obtención del Modelo Tridimensional de Una Pieza de Terracota Mediante Tecnología Láser Escáner 3D; Universidad Politécnica de Madrid: Madrid, Spain, 2014.

54. Gaiani, M.; Balzani, M.; Uccelli, F. Reshaping the Coliseum in Rome: An integrated data capture and modeling method at heritage sites. Comput. Graph. Forum 2000, 19, 369-378. [CrossRef]

55. Pavlidis, G.; Koutsoudis, A.; Arnaoutoglou, F.; Tsioukas, V.; Chamzas, C. Methods for 3D digitization of Cultural Heritage. J. Cult. Herit. 2007, 8, 93-98. [CrossRef]

56. Buill, F.; Andrés, M.N. Aplicación del láser escáner terrestre para levantamientos arquitectónicos, arqueológicos y geotécnicos. Mapping 2008, 124, 46-49.

57. Cano, R.A. Técnicas y Herramientas de Procesamiento de Nubes de Puntos Tridimensionales. Bachelor's Thesis, University Carlos III de Madrid, Getafe, Spain, 19 February 2016.

58. Curless, B.; Levoy, M. Better optical triangulation through spacetime analysis. In Proceedings of the IEEE International Conference on Computer Vision, Cambridge, MA, USA, 20-23 June 1995; pp. 987-994.

59. Tsai, R.Y. Efficient and accurate camera calibration technique for $3 \mathrm{D}$ machine vision. In Proceedings of the CVPR '86: IEEE Computer Society Conference on Computer Vision and Pattern Recognition, Miami Beach, FL, USA, 22-26 June 1986; pp. 364-374.

60. Bernardini, F.; Rushmeier, H.E. Strategies for registering range images from unknown camera positions. In Proceedings of the Three-Dimensional Image Capture and Applications III, San Jose, CA, USA, 24-25 January 2000; pp. 200-206.

61. Garland, M.; Heckbert, P.S. Surface simplification using quadric error metrics. In Proceedings of the 24th Annual Conference on Computer Graphics and Interactive Techniques, Los Angeles, CA, USA, 3-8 August 1997; pp. 209-216.

62. Tzedaki, V.; Kamara, J.M. Capturing as-built information for a BIM environment using 3D laser scanner: A process model. In Proceedings of the Architectural Engineering Conference 2013, State College, PA, USA, 3-5 April 2013; pp. 485-494.

63. Reeder, G.D.; Nelson, G.A. Implementation Manual 3D Engineered Models for Highway Construction: The Iowa Experience; Iowa State University: Ames, IA, USA, 2015; ISBN 8004574416.

64. Vick, S.M.; Brilakis, I. A Review of linear transportation construction progress monitoring techniques. In Proceedings of the 16th International Conference on Computing in Civil and Building Engineering, Osaka, Japan, 6-8 July 2016; pp. 1106-1113.

65. Gursel, I.; Sariyildiz, S.; Akin, Ö.; Stouffs, R. Modeling and visualization of lifecycle building performance assessment. Adv. Eng. Inform. 2009, 23, 396-417. [CrossRef]

66. Breunig, M.; Borrmann, A.; Rank, E.; Hinz, S.; Kolbe, T.; Schilcher, M.; Mundani, R.P.; Jubierre, J.R.; Flurl, M.; Thomsen, A.; et al. Collaborative multi-scale 3D city and infrastructure modeling and simulation. In Proceedings of the Tehran's Joint ISPRS Conferences of GI Research, SMPR and EOEC 2017, Tehran, Iran, 7-10 October 2017; pp. 341-352.

67. Abdelwahab, H. Intelligent design (4D,5D and beyond) for road design and construction projects: Two case studies. IRF Exam. 2017, 12, 21-25.

68. Young, N.W., Jr.; Jones, S.A.; Bernstein, H.M. Interoperability in the Construction Industry; McGraw Hill Construction: Bedford, MA, USA, 2007.

69. Sadrinooshabadi, S.; Taheri, A. Requirement Management in a Life-Cycle Perspective Using Asset Information Modeling Based on ISO 19650-1 and CoClass. Master's Thesis, Jönköping University, Jönköping, Sweden, 2019.

70. Alashwal, A.; Hamzah, A.R. Developing a Conceptual Framework of Fragmentation in Construction. 2014. Available online: https://www.library.auckland.ac.nz/external/finalproceeding/Files/Papers/46530final00176. pdf (accessed on 1 November 2020).

71. Naghshbandi, S.N. BIM for facility management: Challenges and research gaps. Civ. Eng. J. 2016, 2, 679-684. [CrossRef]

72. Shen, W.; Hao, Q.; Mak, H.; Neelamkavil, J.; Xie, H.; Dickinson, J.; Thomas, R.; Pardasani, A.; Xue, H. Systems integration and collaboration in architecture, engineering, construction, and facilities management: A review. Adv. Eng. Inform. 2010, 24, 196-207. [CrossRef] 
73. Talamo, C.; Bonanomi, M. Knowledge Management and Information Tools for Building Maintenance and Facility Management; Springer: Berlin, Germany, 2015; ISBN 9783319239590.

74. Volk, R.; Stengel, J.; Schultmann, F. Building Information Modeling (BIM) for existing buildings-Literature review and future needs. Autom. Constr. 2014, 38, 109-127. [CrossRef]

75. Xu, J. Research on application of BIM 5D technology in Central Grand Project. Procedia Eng. 2017, 174, 600-610. [CrossRef]

76. Amaro, G.G.; Raimondo, A.; Erba, D. Il BIM per il Fire Engineering e per il Safety Management. Ingenio $2017,51$.

77. Bottaccioli, L.; Aliberti, A.; Ugliotti, F.; Patti, E.; Osello, A.; Macii, E.; Acquaviva, A. Building Energy Modelling and Monitoring by Integration of IoT Devices and Building Information Models. In Proceedings of the 2017 IEEE 41st Annual Computer Software and Applications Conference (COMPSAC), Turin, Italy, 4-8 July 2017; pp. 914-922.

78. Milgram, P.; Takemura, H.; Utsumi, A.; Fumio, K. A class of displays on the reality-virtuality continuum. In Proceedings of the Telemanipulator and Telepresence Technologies, Boston, MA, USA, 21 December 1995; Witmer \& Singer: Orlando, FL, USA, 1994; Volume 2351, pp. 282-292.

79. Jensen, P.A. Organisation of facilities management in relation to core business. J. Facil. Manag. 2011, 9, 78-95. [CrossRef]

80. Dewulf, G.; Krumm, P.; Jonge, H. Successful Corporate Real Estate Strategies; Arko Publishers: London, UK, 2000; pp. 1-13.

81. Den Heijer, A.; Tzovlas, G. The European Campus. Heritage and Challenges; Delft University of Technology: Delft, The Netherlands, 2014; ISBN 9789081728324.

82. Organisation for Economic Co-operation and Development (OECD). How are Countries around the World Supporting Students in Higher Education? Organisation for Economic Co-operation and Development (OECD): Paris, France, 2012.

83. University Herald. Study in Georgia System Shows Vast Underutilization of Classrooms. 2013. Available online: http://www.universityherald.com/articles/3327/20130525/study-georgia-system-showsvast-underutilization-classrooms.htm (accessed on 1 October 2013).

84. Neary, M.; Harrison, A.; Crellin, G.; Parekh, N.; Saunders, G.; Duggan, F.; Williams, S.; Austin, S. Learning Landscapes in Higher Education: Clearing Pathways, Making Spaces, Involving Academics in the Leadership, Governance and Management of Academic Spaces in Higher Education; University of Lincoln, Centre for Educational Research and Development: Lincoln, UK, 2010.

85. Harrison, A.; Hutton, L. Design for the Changing Educational Landscape: Space, Place and the Future of Learning; Routledge: Abingdon, UK, 2013; Volume 9780203762, ISBN 9780203762653.

86. Nie, X. Research on smart campus based on cloud computing and internet of things. Appl. Mech. Mater. 2013, 380-384, 1951-1954. [CrossRef]

87. Liu, Y.L.; Zhang, W.H.; Dong, P. Research on the construction of smart campus based on the internet of things and cloud computing. Appl. Mech. Mater. 2014, 543-547, 3213-3217. [CrossRef]

88. Alghamdi, A.; Shetty, S. Survey toward a smart campus using the internet of things. In Proceedings of the 2016 IEEE 4th International Conference on Future Internet of Things and Cloud (FiCloud), Vienna, Austria, 22-24 August 2016; pp. 235-239.

89. CaţǍ, M. Smart university, a new concept in the Internet of Things. In Proceedings of the 201514 th RoEduNet International Conference-Networking in Education and Research (RoEduNet NER), Craiova, Romania, 24-26 September 2015; pp. 195-197.

90. Rehman, A.U.; Abbasi, A.Z.; Shaikh, Z.A. Building a smart university using RFID technology. In Proceedings of the 2008 International Conference on Computer Science and Software Engineering, Wuhan, China, 12-14 December 2008; Volume 5, pp. 641-644.

91. Du, S.; Meng, F.; Gao, B. Research on the application system of smart campus in the context of smart city. In Proceedings of the 2016 8th International Conference on Information Technology in Medicine and Education (ITME), Fuzhou, China, 23-25 December 2016; pp. 714-718.

92. Malatji, E.M. The development of a smart campus-African universities point of view. In Proceedings of the 2017 8th International Renewable Energy Congress (IREC), Amman, Jordan, 21-23 March 2017.

93. Coccoli, M.; Guercio, A.; Maresca, P.; Stanganelli, L. Smarter universities: A vision for the fast changing digital era. J. Vis. Lang. Comput. 2014, 25, 1003-1011. [CrossRef] 
94. Atif, Y.; Mathew, S.S.; Lakas, A. Building a smart campus to support ubiquitous learning. J. Ambient Intell. Humaniz. Comput. 2015, 6, 223-238. [CrossRef]

95. Al Shimmary, M.K.; Al Nayar, M.M.; Kubba, A.R. Designing Smart University using RFID and WSN. Int. J. Comput. Appl. 2015, 112, 975-8887.

96. Manqele, L.; Dlodlo, M.; Manqle, L.; Coetzee, L.; Williams, Q.; Sibiya, G. Preference-based Internet of Things dynamic service selection for smart campus. In Proceedings of the IEEE AFRICON Conference, Addis Ababa, Ethiopia, 14-17 September 2015; Volume 2015.

97. Zhang, Y.; Guo, M. The research of smart campus based on internet of things \& cloud computing. In Proceedings of the 11th International Conference on Wireless Communications, Networking and Mobile Computing (WiCOM 2015), Shanghai, China, 21-23 September 2015; p. 6.

98. Torres-Sospedra, J.; Avariento, J.; Rambla, D.; Montoliu, R.; Casteleyn, S.; Benedito-Bordonau, M.; Gould, M.; Huerta, J. Enhancing integrated indoor/outdoor mobility in a smart campus. Int. J. Geogr. Inf. Sci. 2015, 29, 1955-1968. [CrossRef]

99. Sastra, N.P.; Wiharta, D.M. Environmental monitoring as an IoT application in building smart campus of Universitas Udayana. In Proceedings of the 2016 International Conference on Smart Green Technology in Electrical and Information Systems (ICSGTEIS), Bali, Indonesia, 6-8 October 2016; pp. 85-88.

100. Academic Ranking of World Universities. Available online: http://www.shanghairanking.com/ Shanghairanking-Subject-Rankings/civil-engineering.html (accessed on 19 August 2020).

101. Brown, T. Desing Thinking. Harv. Bus. Rev. 2009, 86, 9.

102. Al-Shalabi, F.A.; Turkan, Y.; Laflamme, S. BrIM Implementation for Documentation of Bridge Element Condition for Inspection. In Proceedings of the 5th International Construction Specialty Conference of the Canadian Society for Civil Engineering (ICSC), Vancouver, BC, Canada, 8-10 June 2015.

103. Kitsakis, D.; Dimopoulou, E. Addressing public law restrictions within a 3D cadastral context. ISPRS Int. J. Geo-Inf. 2017, 6, 182. [CrossRef]

Publisher's Note: MDPI stays neutral with regard to jurisdictional claims in published maps and institutional affiliations.

(C) 2020 by the authors. Licensee MDPI, Basel, Switzerland. This article is an open access article distributed under the terms and conditions of the Creative Commons Attribution (CC BY) license (http://creativecommons.org/licenses/by/4.0/). 